\title{
The Monotonicity Puzzle: An Experimental Investigation of Incentive Structures
}

\author{
Jeannette Brosig, Department of Economics, University of Duisburg-Essen, Germany, E-Mail: jeannette.brosig@ibes.uni-due.de \\ Christian Lukas, Department of Economics, University of Konstanz, Germany, E-Mail: christian.lukas@uni-konstanz.de \\ Thomas Riechmann, Department of Business Studies and Economics, University of Kaiserslautern, Germany, E-Mail: \\ riechmann@wiwi.uni-kl.de
}

\begin{abstract}
Non-monotone incentive structures, which - according to theory - are able to induce optimal behavior, are often regarded as empirically less relevant for labor relationships. We compare the performance of a theoretically optimal non-monotone contract with a monotone one under controlled laboratory conditions. Implementing some features relevant to real-world employment relationships, our paper demonstrates that, in fact, the frequency of income-maximizing decisions made by agents is higher under the monotone contract. Although this observed behavior does not change the superiority of the non-monotone contract for principals, they do not choose this contract type in a significant way. This is what we call the monotonicity puzzle. Detailed investigations of decisions provide a clue for solving the puzzle and a possible explanation for the popularity of monotone contracts.
\end{abstract}

Keywords: experimental agency, non-monotone contracts

Manuscript received February 11, 2009, accepted by Rainer Niemann (Accounting) February 10,2010 .

\section{Introduction}

In the field of labor contracts, an important classification is the one of monotone and non-monotone contracts. Monotone contracts grant higher pay to workers with higher effort input or output, respectively. As a consequence, the best performer receives the highest pay. Under non-monotone contracts this is not the case. Contract theory research has shown that there are various contractual relationships where monotone contracts are not the optimal choice. The conditions - the monotone likelihood-ratio property and the convexity of the distribution function - are discussed by Grossman and Hart (1983), while the optimality of linear contracts as a variant of monotone contracts is discussed by Christensen and Feltham (2005, ch.19), Hart and Holmström (1987), or Holmström and Milgrom (1987). Referring to multi-period problems which are the focus of our study, complementarities and/or correlation between periods can also give rise to non-monotonicity in contracts.
Assume that the production outcome realized in period 1 is positively correlated with the production outcome realized in period 2. Assume further that each outcome can be either low or high. The employee ('agent') influences the outcome by her effort choice which also can be either low or high. Due to the correlation between periods, a high (low) outcome in period 1 will likely be followed by a high (low) outcome in period 2. That is, the probability to achieve a high outcome in period 2 is lower if the outcome in period 1 is low, and vice versa. As a consequence, it takes a higher bonus to motivate the agent to expend high effort if the first period outcome had been low than if the first period outcome had been high. Given the agent succeeds in period 2 after a low outcome in period 1 , her realized bonus payment could be higher than the one that she had achieved after a high outcome in both periods. Such a non-stationarity of the production technology (i.e., the interdependency of period outcomes) represents a likely feature of quite a number of settings where, e.g., 
learning-on-the-job occurs (e.g., due to technological advance, organizational restructuring, or employee turnover). A specific example would be a marketing manager who learns about consumer tastes in period 1 while already being in charge of the company's key accounts. The more she learns in period 1 the more likely are high sales in period 1 and period 2. In the case she does not meet the sales target in period 1, the marketing manager appears poorly informed about consumer tastes. High sales in period 2 are then rather uncertain. Therefore, it takes high incentives to induce high effort in period 2, and the state contingent payment resulting from a low outcome in period 1 and a high outcome in period 2 will be higher than the payment resulting from a high outcome in both periods.

An argument in favor of monotone contracts is the 'free disposal of output' assumption which plays a major role in general equilibrium theory (Arrow and Hahn 1980: 20). In fact, even outputinsensitive contracts can be optimal in settings employing this assumption (Nachman and Noe 1995). However, with a stationary production technology (i.e., independent periods), the monotone likelihood ratio property (MLRP) and free disposal are basically equivalent. If higher effort makes higher outputs more likely (MLRP), the effort choice is equivalent to an unrestricted form of free disposal (Nachman and Noe 1995: 319). Now if that holds for every period without dynamic (overlapping) effects, resulting optimal contracts are monotone in output (Holmström and Milgrom 1987). However, as our example illustrates, once the periods become interdependent, monotone contracts do not necessarily implement the theoretically optimal solution.

For practical purposes, however, non-monotone contracts are often deemed implausible. In fact, monotone contracts are in frequent use while, to our knowledge, there are only few non-monotone contractual relations. For example, there are econometric studies indicating that non-monotone contracts are used, but these studies do not focus on individual contracts, but estimate certain parameters thereof (Prendergast 2002: 1077 et seq.; Leonard 1990). The popularity of piece rates, target bonuses as percentage of base salary, or variable ratios or quotas (with constant targeted level of performance) are evidence of linear contracts. One possible reason for the predominance of monotone contracts could be that, in order to obtain non-monotonicity on an individual level, individual performance needs to be rewarded. In many of the employed profit-sharing plans, individual performance is not measured or, at least, not rewarded, however. In addition, concerns for horizontal equity might prevent individual nonmonotone contracts because a violation of horizontal equity may undermine employee motivation (Baker, Jensen, and Murphy 1988: 596). Motivated by this background, Lukas (2007a) directly compares the performance of monotone and nonmonotone contracts in a controlled laboratory experiment. He demonstrates that the majority of employers, in fact, select the non-monotone contract. Moreover, the majority of employees act as income-maximizers (i.e., they choose high instead of low effort) - despite the non-monotonicity of contracts. Our study builds on this research and tries to close the gap between the empirically observed predominance of monotone contracts and the experimental evidence. To do that, we implement an environment entailing some features which are more natural for employment relationships. Before presenting the details of our experimental design, the next paragraph provides an overview of related research.

The widespread use of monotone contracts in practice has led many authors to focus on these types of contracts only. Among others, much theoretical research has been carried out in the LEN framework in agency theory where linear contracts allow for analytical tractability. Linear contracts are a characteristic feature of the approach (Dutta and Reichelstein 2003; Feltham and Xie 1994; or Indjejikian and Nanda 1999). Recent examples include Sabac (2007) or Feltham and Hofmann (2007). Incentive effects of linear contracts have also been analyzed in various empirical studies. Many of these investigations reveal a positive correlation between monetary rewards and effort (see, e.g., Bailey, Brown, and Cocco 1998; Lazear 2000; Sprinkle 2000), whereas others do not find any positive effects (Bonner, Hastie, Sprinkle, and Young 2000; Jenkins, Mitra, Gupta, and Shaw 1998). A positive relationship between rewards and effort is also reported in experimental analyses of contractual relationships (e.g., Fehr, Kirchsteiger, and Riedl 1993, 1998), though the evidence suggests that its degree is quite sensitive to the institutional setting (e.g., Van der Heijden, Nelissen, 
Potters, and Verbon 2001; Charness, Frechette, and Kagel 2004). Models that try to account for the observed behavior include some form of otherregarding preferences like a concern for relative payoffs (e.g., Fehr and Schmidt 1999; Bolton and Ockenfels 2000), some sort of reciprocity (e.g., Rabin 1993; Levine 1998; Falk and Fischbacher 1998), or both reciprocity and efficiency concerns (Charness and Rabin 2002).

Many of the experimental studies in contract or agency theory directly relate compensation to observable (and verifiable) effort inputs (see also Fehr, Klein, and Schmidt 2004; Falk and Gächter 2002; Huck, Seltzer, and Wallace 2004). Employment relationships featuring observability of effort and making compensation dependent on effort have to rely on subjective performance evaluation. In spite of the growing literature on observable effort inputs, most of the research in agency theory assumes unobservability of the agents' effort choices and availability of verifiable performance measures. Due to effort unobservability, in these models of the principal-agent type, output is relevant for compensation, while input only has an indirect influence. The studies conducted by Güth, Klose, Königstein, and Schwalbach (1998) and by Anderhub, Gächter, and Königstein (2002) deal with incentive effects of output-contingent pay based on monotone contracts. Keser and Willinger (2000) allow for non-monotone contracts, but these contracts do not represent (incentive-) compatible offers. Lukas (2007a) provides the first study on the effects of incentive compatible nonmonotone contracts. As mentioned above, some features relevant for real-world employment relationships are not included in his study, however. For example, employers adjust incentive plans usually on an annual basis and, thus, do not need to stick to an arrangement for all times. Moreover, employees generally are free to leave their job within certain restrictions of time, that is they can effectively reject contract offers which they deem unacceptable. We implement these features in our experimental design and, thereby, move the setting closer to reality. At the same time, decision-making becomes easier for participants because they get more information, more chances to learn from experience, and the opportunity to change their decisions if they want to. One might speculate whether and how these features impact decisions and outcomes. Given the increased ease of decision-making, there might be even stronger evidence in favor of non-monotone contracts.

In our experiment principals could choose between a theoretically optimal non-monotone and a theoretically sub-optimal monotone contract. In line with Lukas (2007a), our data demonstrate that agents virtually never reject contract offers and often choose high effort as intended by the principals. This behavior turns out to be quite robust against the different variations of our experimental design, though it is more pronounced under the monotone contract. The observed agents' behavior does not lead to higher expected payoffs for principals under the monotone contract, however. In fact, the expected payoff for principals is still higher under the non-monotone contract. Accordingly, principals are predicted to select the non-monotone contract. This is not what we observe. As such our results shed light on the delicate interplay between incentives, behavior, and performance and demonstrate that, despite the optimality of nonmonotone contracts, monotone contracts might still be implemented - a behavioral pattern which we call the 'monotonicity puzzle'. From our point of view this puzzle can be resolved as follows: Experiments with observable effort show a positive correlation between effort and reward. If effort is not observable, output is used to infer input and, consequently, serves as a proxy for effort. Fairness considerations, which have been identified in observable effort experiments, would then suggest monotone contracts so that higher effort proxied by output - leads to higher rewards. As long as the theoretically optimal contract is indeed monotone (in outcomes), the effort proxy will do just fine. However, as soon as a non-monotone contract is optimal the effort proxy leads to a suboptimal contract design. This is what we observe in our experiment.

Our findings contribute to the research on agency theory and on labor markets by demonstrating that agents tend to respond to the incentives given by non-monotone contracts and, consequently, that this type of contract may not be as implausible as it is often regarded to be. Our observations on principals, however, might help to understand why this type of contract is rarely used in labor markets, nevertheless. The paper is structured as follows. Section 2 contains a description of the contract design and its implementation. In sections 3 and 4 we present the experimental design and derive 
our hypotheses. Section 5 discusses the results on agents' and principals' behavior and the final section concludes.

\section{Design of contracts}

Our experiment covers a situation, where a nonmonotone contract is optimal from a theoretical perspective (see, e.g., the learning-on-the-job example given in the introduction). The analytical model underlying our contract design is adopted from Lukas (2007b). According to this model, an agent can choose between "effort" and "no effort" in each of the two periods the contract lasts. The agent's effort decision affects the outcome distribution. The principal is unable to observe and verify the agent's effort, so he relies on outputcontingent compensation. Given a binary output set in each period - the outcome can be either low $(L)$ or high $(H)$ - there are four different outcome sequences $i j, i, j=L, H$, where $x_{1}=x^{i}$ indicates first-period outcome and $x_{2}=x^{j}$ the secondperiod outcome. Table 1 lists the probabilities to achieve a given outcome sequence contingent on the agent's effort choices. They are obtained by setting $\alpha=2, \beta=1, q=2, e_{1}=1, e_{0}=0, p_{1}=1$, and $p_{0}=0.68$ in Lukas' (2007b) model. Following Lukas (2007b), let $e_{i}, i \in 0 ; 1$ indicate first-period effort while $p_{j}, j \in 0 ; 1$ indicates second-period effort. The probability to achieve the high outcome in period 1 equals

$$
P\left(x_{1}=x^{H}\right)=\frac{\alpha+q e_{i}}{\alpha+\beta+q},
$$

and in period 2

$$
P\left(x_{2} \mid x_{1}=x^{H}\right)=p_{j} \frac{\alpha+q e_{i}+1}{\alpha+\beta+q+1}
$$

and

$$
P\left(x_{2} \mid x_{1}=x^{L}\right)=p_{j} \frac{\alpha+q e_{i}}{\alpha+\beta+q+1},
$$

respectively. In the model $\alpha$ and $\beta$ represent parameters of a beta distribution which are affected by the agent's effort and updating after observing first-period outcome following DeGroot (1970: 160).

For deriving the theoretical predictions, we assume risk neutrality for both the principal and the agent. Note that, there are a number of experiments indicating that subjects tend to be riskaverse. With our parametrization, risk-aversion would not change the theoretical prediction regarding principals' and agents' behavior, however. In fact, with risk-aversion, a principal would be even more likely to choose the non-monotone contract. Let $s^{i j}$ denote the salary received by the agent at the beginning of period 1 based on the outcome sequence $i j$. The cost of exerting effort for the agent is set equal to 0.45 , i.e. exerting effort in both periods leads to effort cost of 0.90. Now optimal payments (i.e., payments that induce high effort by the agent in both periods at minimal costs) can be calculated. For period 2, incentive-compatible pay differences can be obtained by

$$
\left(s^{H H}-s^{H L}\right)=\frac{0.45}{0.83-0.57}=1.7
$$

and

$$
\left(s^{L H}-s^{L L}\right)=\frac{0.45}{0.67-0.45}=2.05 .
$$

For period 1, the incentive-compatible pay difference amounts to

$$
\begin{aligned}
& \left(s^{H L}-s^{L L}\right) \\
& =\frac{\left[\begin{array}{c}
2 \cdot 0.45-(0.8 \cdot 0.83-0.4 . \\
0.34) \cdot 1.7-[(1-0.8) \cdot 0.67-(1- \\
0.4) \cdot 0.23] \cdot 2.05
\end{array}\right]}{0.8-0.4} \\
& =0.03 .
\end{aligned}
$$

With a zero reservation wage, resulting payments are $s^{L L}=0, s^{H L}=0.03, s^{L H}=2.05$, and $s^{H H}=$ 1.73 .

Such a pay schedule could have led to negative payoffs for agents since providing effort in both periods implies effort costs of 0.90 , but realizing the worst possible outcome sequence generates a zero income. To ensure a non-negative payoff we raise all payments by 0.90 (which does not affect incentive compatibility). Theoretically, agents facing binding incentive compatibility constraints are assumed to select the action desired by the principal. To provide sensible incentives in the laboratory, another 0.35 is added to $s^{L H}$, while $s^{H L}$ is increased by 0.37 (which increases $s^{H H}$ by the 
Table 1: Contract structures

\begin{tabular}{ccccc} 
period 1 & $P\left(x_{1}=x^{H}\right)$ & period 2 & $P\left(x_{2}=x^{H} \mid x_{1}=x^{H}\right)$ & $P\left(x_{2}=x^{H} \mid x_{1}=x^{L}\right)$ \\
\hline effort & 0.8 & effort & 0.83 & 0.67 \\
\hline no effort & 0.4 & no effort & 0.57 & 0.45 \\
\hline & & effort & 0.50 & 0.33 \\
\hline
\end{tabular}

same amount). The parameterization leads to

(7)

$$
s^{L L}=0.90,
$$$$
\text { (8) } s^{H L}=1.30 \text {, }
$$$$
\text { (9) } s^{L H}=3.40 \text {, }
$$$$
\text { (10) } s^{H H}=3.00 \text {. }
$$

Payments (7)-(10) represent contract $N$ - the nonmonotone contract in our experiment. By assumption, the corresponding payments to the principal amount to $s_{P}^{L L}=0.60, s_{P}^{H L}=s_{P}^{L H}=1.20$, and $s_{P}^{H H}=1.80$, i.e $x^{L}=0.30, x^{H}=0.90$. These payments to the principal ensure that a high outcome is equally desirable for him irrespective of its timing. Of course, many more incentive compatible contracts could have been derived and possibly tested. As the model is general in nature, its predictions (should) hold for any particular contract solving the principal's problem.) In the experiment, contract information about (non-)monotonicity is not given to all participants alike. To have the same labels in all treatments without indicating contract properties, we labeled the non-monotone contract as contract $X$ and the monotone contract as contract $Y$ in the instructions. For exposition, we label the contracts in the paper as $N$ (non-monotone) and $M$ (monotone), respectively.

Contract $M$ - the monotone contract - was obtained by setting the agent's payment $s^{L H}=3.00$ and $s^{H H}=3.40$. It is given by

(11) $s^{L L}=0.90$,

(12) $s^{H L}=1.30$,

(13) $s^{L H}=3.00$,

(14) $s^{H H}=3.40$.

Consequently, the principal's payments change to $s_{P}^{L H}=1.60$ and $s_{P}^{H H}=1.40$. That is, to transform an optimal non-monotone contract into a monotone one, the principal needs to settle with less given the most favorable outcome sequence $\left(x^{H}, x^{H}\right)$, but he receives more under an initially less favorable sequence $\left(x^{L}, x^{H}\right)$. Incentive com- patibility is still preserved under the monotone contract $M$.

Note that the probabilities to achieve each possible outcome sequence do not depend on the contract. They and the net payoffs under each contract are illustrated in Fig.1 and explicitly given in Tables B and B in Appendix B. Expected payoffs for the agent can be easily calculated now.

\subsection{Agent's payoffs}

By applying backward induction in expected payoffs to both contracts, we can deduce our hypotheses. The following calculations refer to the game trees given in Fig.1

Referring to stage-two decision nodes, Table 2 illustrates the agents' expected net payoffs under contract $N$. These net payoffs can be used to determine the agent's income-maximizing strategy in stage 1 (decision node $W$ ). Since the expected payoff when choosing 'no effort' ( $€$ 1.64) at this stage is lower than the expected payoff when choosing 'effort' (€ 1.79), the income-maximizing strategy is to choose 'effort'. That is, income-maximizing agents under contract $N$ choose 'effort' in stage 1 and 'effort' in stage 2. If an agent selects 'no effort' in stage 1 instead and reaches decision node $N E_{L}$ or $N E_{H}$, respectively, it is payoff-maximizing to select 'no effort' in stage 2.

Table 2: Contract $N$. Expected net payoffs to agent in stage 2 given stage-1 decision

\begin{tabular}{cccc} 
node & \multicolumn{2}{c}{ expected payoff } & income- \\
& no effort & effort & $\begin{array}{c}\text { maximizing } \\
\text { action }\end{array}$ \\
\hline$N E_{L}$ & 1.475 & 1.275 & no effort \\
\hline$N E_{H}$ & 1.878 & 1.700 & no effort \\
\hline$E_{L}$ & 1.575 & 1.675 & effort \\
\hline$E_{H}$ & 1.819 & 1.811 & (no effort) \\
\hline
\end{tabular}

Referring to stage-two decision nodes, Table 3 illustrates the agents' expected net payoffs under 
Figure 1: Game trees for the contracts

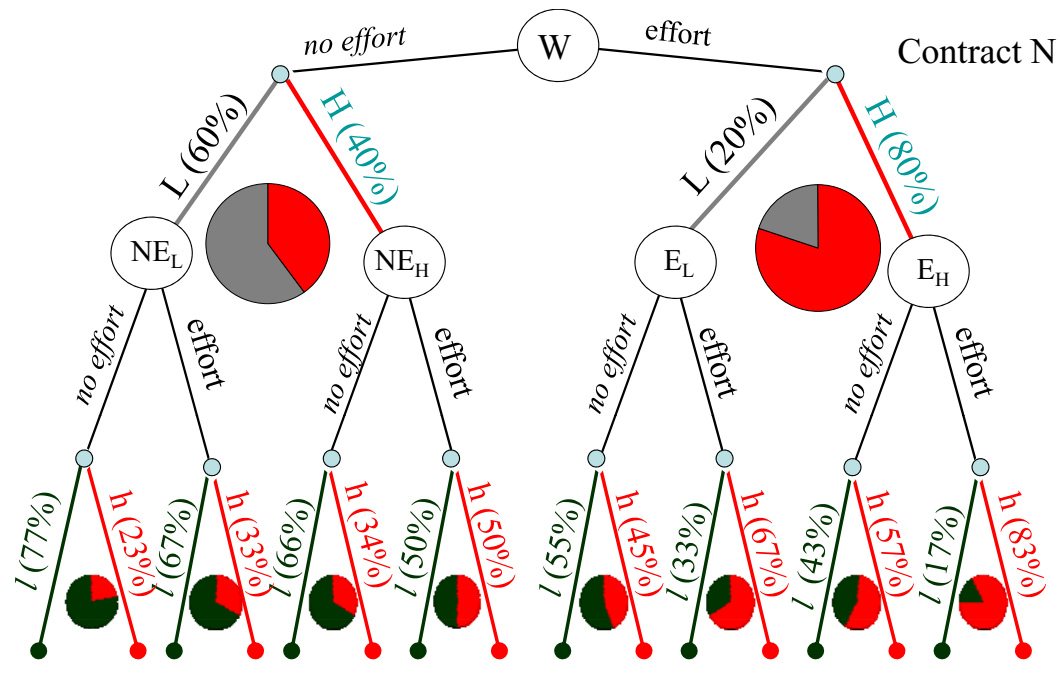

$\begin{array}{llllllllllllllll}0.60 & 1.20 & 0.60 & 1.20 & 1.20 & 1.80 & 1.20 & 1.80 & 0.60 & 1.20 & 0.60 & 1.20 & 1.20 & 1.80 & 1.20 & 1.80\end{array}$

$\begin{array}{llllllllllllllll}0.90 & 3.40 & 0.45 & 2.95 & 1.30 & 3.00 & 0.85 & 2.55 & 0.45 & 2.95 & 0.00 & 2.50 & 0.85 & 2.55 & 0.40 & 2.10\end{array}$

The upper row contains payoffs for the first mover; the lower row the payoffs for the second mover.

(a) Contract N (non-monotone)

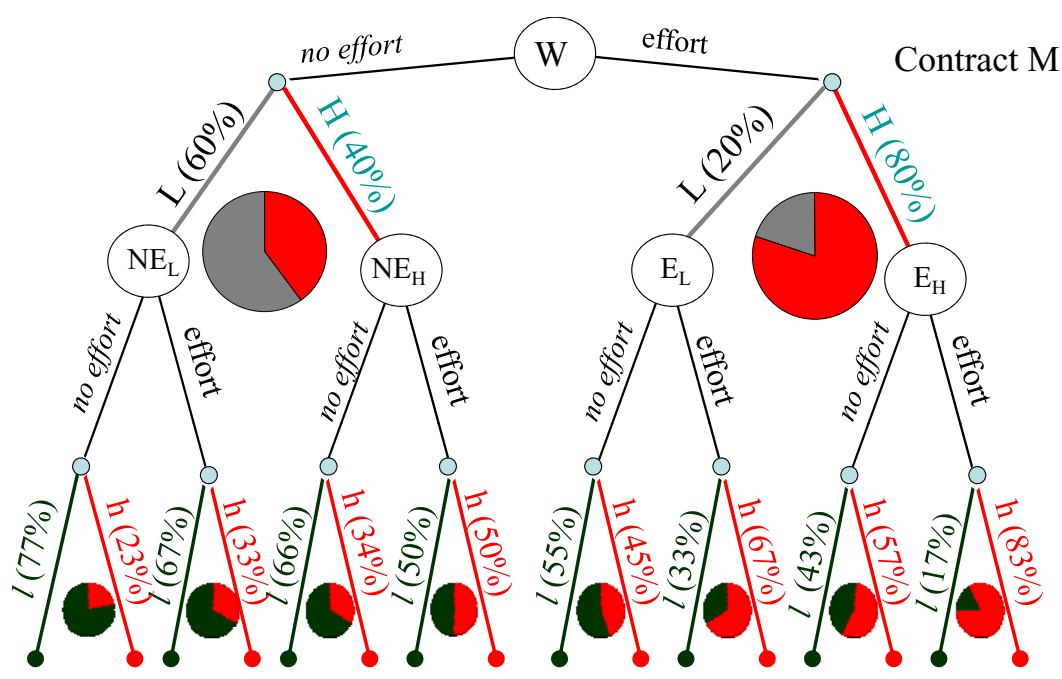

$\begin{array}{llllllllllllllll}0.60 & 1.60 & 0.60 & 1.60 & 1.20 & 1.40 & 1.20 & 1.40 & 0.60 & 1.60 & 0.60 & 1.60 & 1.20 & 1.40 & 1.20 & 1.40\end{array}$ $\begin{array}{llllllllllllllll}0.90 & 3.00 & 0.45 & 2.55 & 1.30 & 3.40 & 0.85 & 2.95 & 0.45 & 2.55 & 0.00 & 2.10 & 0.85 & 2.95 & 0.40 & 2.50\end{array}$

The upper row contains payoffs for the first mover; the lower row the payoffs for the second mover.

(b) Contract M (monotone) 
contract $M$.

Table 3: Contract $M$. Expected net payoffs
to agent in stage 2 given stage-1 decisions

\begin{tabular}{cccc} 
node & \multicolumn{2}{c}{ expected payoff } & income- \\
& no effort & effort & $\begin{array}{c}\text { maximizing } \\
\text { action }\end{array}$ \\
\hline$N E_{L}$ & 1.383 & 1.143 & no effort \\
\hline$N E_{H}$ & 2.014 & 1.900 & no effort \\
\hline$E_{L}$ & 1.395 & 1.407 & (effort) \\
\hline$E_{H}$ & 2.047 & 2.143 & effort \\
\hline
\end{tabular}

Again, expected net payoffs can be used to determine the agent's income-maximizing strategy in stage 1 . Since the expected payoff when choosing 'no effort' (1.64) at this stage is lower than the expected payoff when choosing 'effort' (2.00), the income-maximizing strategy is to choose 'effort'. That is, income-maximizing agents under contract $M$ also choose 'effort' in stage 1 and 'effort' in stage 2. If an agent selects 'no effort' in stage 1 instead and reaches decision node $N E_{L}$ or $N E_{H}$, respectively, it is payoff-maximizing to select 'no effort' in stage 2 as well.

\subsection{Principals' payoffs}

To predict principals' choices, one can easily verify that no contract dominates the other in terms of first-order stochastic dominance or second-order stochastic dominance for any effort strategy selected by agents. Given the decisions of incomemaximizing agents, the expected payoffs for principals selecting contract $N$ is $€ 1.56$ and for principals selecting contract $M$ is $€ 1.35$. (The principal's decrease in expected surplus of $€ 0.21$ associated with choosing $M$ instead of $N$ is exactly the increase of the agent's expected surplus of $€$ o.21.)

\section{Experimental design}

We test five different treatments of the sequential principal-agent game with ten decision rounds each. The basic set-up is as follows: The first mover (principal) has to choose between two similar, incentive compatible contracts $N$ and $M$. Contract $N$ is characterized by the pay structure given in (7)-(10), whereas (11)-(14) characterizes M's pay structure. That is, contract $N$ awards the highest payoff to the output sequence $\{$ low, high $\}$ and contract $M$ does so to the sequence $\{$ high, high\}. The contract choice determines the payoff for both the first mover and the second mover (agent) for every possible output sequence. The second mover's effort decision influences the probabilities of the different possible output sequences. In order to get enough observations for agents' behavior in stage 2, we applied the strategy method when asking for agents' effort decision at this stage. That is, agents had to state their effort decision for each of the two possible outcomes that could result in stage 1. Table 4 summarizes treatments and sample sizes. Our first treatment is labeled 'no framing with selected contract information' (NFS) and serves as our baseline treatment. In NFS, an agent is matched with the same principal in all ten rounds. The principal decides on a contract once and for all rounds and the agent receives information only on the contract chosen by the principal, i.e. agents are given a game-tree visualization of that contract containing probabilities of success and respective payoffs for both players (see Figures 1(a) and 1(b)). The agent must accept the contract offered. 'No framing' means that subjects do not receive explicit information on the (non-)monotonicity property of the contract. In these respects, the treatment NFS is comparable to the 'framing principal' treatment employed by Lukas (2007a) in which framing refers to labeling a principal an 'employer' who selects a contract (a feature which is also used in our design); but in our treatment parameters were chosen in a way that the non-monotonicity is more explicit (i.e., in contract $N$ ), which increases practical relevance of results. Our controlled variations of the baseline treatment allow us to investigate the influence of different features that are not only relevant to the labor-market context, but that could also help to reduce the complexity of the experimental situation. As such, the results might explain the differences between the experimental data obtained in Lukas (2007a) and the empirically observed predominance of monotone contracts. The second treatment ('framing with selected contract information', $F S$ ) differs from the first one only in that additional information about the contract type is given to the participants, i.e. contracts are explicitly framed as either 'monotone' or 'non-monotone', respectively. The framing also includes information about the agent's net payoffs for outcome sequences $\left(x^{L}, x^{H}\right)$ and $\left(x^{H}, x^{H}\right)$ based on the respective effort choices. Principals receive this information for both contracts, while 
Table 4: Summary of treatments and sample sizes

\begin{tabular}{|c|c|c|c|c|c|c|}
\hline Treatment & $\begin{array}{l}\text { Inform. on contract } \\
\text { type given to agents }\end{array}$ & $\begin{array}{l}\text { Opportunity to } \\
\text { reject contract }\end{array}$ & Matching & $\begin{array}{c}\text { \# of } \\
\text { subjects }\end{array}$ & $\begin{array}{l}\text { \# of ind } \\
\text { agents }\end{array}$ & $\begin{array}{l}\text { endent obs. } \\
\text { principals }\end{array}$ \\
\hline NFS & none & no & fixed & 40 & 20 & 20 \\
\hline FS & for selected contract & no & fixed & 38 & 19 & 19 \\
\hline $\mathrm{FC}$ & for both contracts & no & fixed & 38 & 19 & 19 \\
\hline FCR & for both contracts & no & random & 72 & 12 & 12 \\
\hline FCRR & for both contracts & yes & random & 72 & 12 & 12 \\
\hline
\end{tabular}

agents receive it only for the contract selected by their principal. None of the treatments investigated in Lukas (2007a) contains information of this kind. One might argue that the information about contract properties should not affect behavior since it could be derived from an inspection of the numbers given in the contract. There are two reasons why this does not have to be the case. First, participants might perceive both contracts as monotone contracts. A prominent example of misperception despite readily available numbers is represented by de Bartolome's (1995) study on average vs. marginal tax rates and people's labor supply decisions. Second, an explanation of the characteristics of the contract and/or an visualization by tabulating numbers might ease the understanding and can even be found in executive compensation contracts (e.g., Balsam 2002: 113). Hence, an explicit information on contract properties may well matter.

In the third treatment ('framing with complete information', $F C$ ), agents receive the same information as in treatment $F S$, but this time for both contracts. That is, they receive information also about the contract not chosen by the principal. As in treatment FS, information included game trees and the explanation of the (non-)monotonicity property of contracts. The variation in this treatment reflects the fact that, in negotiations between employees and employers, both usually know the characteristics of the contracts available to the employer.

In the fourth treatment ('framing with complete information, random interaction', FCR), agents receive the same information as in treatment $F C$, but here the pairs of principal and agent are randomly formed anew for each of the ten decision rounds. This design allows principals to learn about the consequences of their contract choice and it allows agents to learn about the different principals' de- cisions as it is often the case in labor markets. This design feature might further ease the participants' understanding.

The fifth treatment ('framing with complete information, random interaction, and rejection opportunity', FCRR) is the same as FCR, but additionally includes the opportunity for agents to reject contract offers. Such a rejection opportunity maps real-life employees' statutory right to quit an employment relationship at their will (although certain time restrictions may apply). Costs of contract termination might be incurred by both parties: the employer needs to fill in the vacant position which might lead to costs for searching, costs for forgone output, etc., and the employee needs to find a new position which might lead to costs as well. That people incur such costs to punish others (i.e., to reduce the other's payoff) is already known from previous experimental research (see, e.g., the numerous rejections of positive offers observed in ultimatum bargaining experiments). Accordingly, the opportunity to reject a contract might be used as a means to punish the principal for his contract choice. In our experiment, choosing the option to reject in a certain round leads to a payment of $€$ 0.50 in this round for the agent and the principal, respectively. Since contract $M$ offers agents a higher expected payoff than contract $N$, we expect agents to reject contract $N$ only, if they reject a contract at all. Under contract $N$, agents' expected payoff is $€ 1.79$, if they select effort in both periods, and $€ 1.64$ if not. Corresponding expected payoffs for principals are $€ 1.56$ and $€ 1$.01, respectively. As such, rejecting contract $N$ constitutes a costly punishment option for agents. Note that "punishment by shirking" is available to the agent in every treatment.

At the beginning of each session, subjects were given a comprehensive presentation by one of the 
experimenters. The presentation was the same for all treatments and was conducted by the same experimenter. It included a detailed explanation of the decision context and the game tree (without the relevant payoffs) and exemplified of how individual decisions influence outcome probabilities and profits. For the latter, participants were guided through the decision tree for each of the two possible choices in period 1 . Then subjects were randomly assigned to their roles and to their seats in the laboratory where they received written instructions and, depending on the treatment, sheets with contracts illustrated as game trees. The structure of the game trees made it more easy to realize (in addition to the explanation given by the experimenter) that contracts differ only by payoffs and not by the probability structure. ${ }^{1}$ After reading the instructions and during the course of the experiment, subjects were given the opportunity to privately ask clarifying questions. They were neither allowed to ask questions in public nor to communicate with other participants.

All experiments were conducted via computers using the zTree-software tool (Fischbacher 2007). On their computer screen, subjects could see their own decision(s), the outcomes of random draws made by the computer, and the resulting payoffs. In addition, agents were informed about the principals' decisions, while principals could not observe the agents' effort choices. That is, principals were only informed about the payoff resulting in each round and, in treatment FCRR, also about the agent's rejection decision. This corresponds to the fundamental assumption of unobservable effort made in agency models. In treatments FCR and FCRR, subjects were randomly re-matched in matching groups consisting of six participants (i.e., three principals and three agents). We made sure that no two participants were matched with each other in two subsequent rounds. Subjects were informed accordingly.

All sessions were run at the Magdeburg Laboratory for Experimental Economics (MaxLab) in June 2006 and in April and July 2007. A total of 260 students recruited via ORSEE (Greiner 2004) from several courses at the University of Magdeburg took part in the experiment. All students had either passed pre-diploma examinations or completed a

1 Original instructions in German are provided as an online supplement. bachelor program. While recruiting participants, we made sure that no student could take part twice in the experiment. The sample size was 20 pairs of subjects in treatment NFS, 19 pairs of subjects in each of the two treatments $F S$ and $F C$, and 36 principals and 36 agents (i.e., 12 matching groups) in each of the two treatments FCR and FCRR. Sessions lasted for about one hour; there were no time constraints imposed on subjects' decision-making. All subjects were anonymously paid off after the experiment. No information was given about the identity of other subjects. Average earnings were $€ 13.77$.

\section{Hypotheses}

The output sequences $\left(x_{1}, x_{2}\right) \in\left\{x^{L}, x^{H}\right\}^{2}$ stochastically depend on the sequence of effort inputs $\left(e_{1}, e_{2}\right) \in\{0,1\}^{2}$. The probabilities of achieving output sequence $\left(x_{1}, x_{2}\right)$ conditional on input sequence $\left(e_{1}, e_{2}\right), \operatorname{Prob}\left(\left(x_{1}, x_{2}\right) \|\left(e_{1}, e_{2}\right)\right)$, are identical in each treatment. The same holds for net payoffs under contract $N$ and $M$, respectively (see section 2). If a contract offer is rejected in treatment $F C R$, both principal and agent have to settle with a fixed payment of $€ 0.50$ each and the decision round ends with the agent's rejection.

As demonstrated in the last section, given the two contracts' incentive compatibility, income maximizing agents always choose 'effort' in stage 1 and 'effort' in stage 2. If an agent selects 'no effort' in stage 1 instead, it is always payoff-maximizing to select 'no effort' in stage 2. Given the expected payoffs resulting from income-maximizing behavior, agents will not reject any contract offered. (Note that rejecting a contract offer yields $€ 0.50$.) The corresponding hypotheses regarding agents' behavior are as follows:

Hypothesis 1 (Agents; Contract Acceptance) Given incentive compatibility of contract $N$ and contract $M$, if agents want to maximize their income they will never reject a contract offer made by principals.

\section{Hypothesis 2 (Agents; Stage 1 Behavior)}

If agents want to maximize their income they will select 'effort' in stage 1.

\section{Hypothesis 3 (Agents; Stage 2 Behavior)}

If agents want to maximize their income they will select 'no effort' in stage 2, if they selected 
'no effort' in stage 1. They will select 'effort' in stage 2, given $E_{L}$ for contract $N$ and given $E_{H}$ for contract $M$. (As the difference in expected payoffs in node $E_{H}$ for contract $N$ is only $€ 0.008$ and in $E_{N}$ for contract $M$ is only $€ 0.012$, we consider both possible choices as 'income-maximizing' in the subsequent analysis.)

The hypothesis for income-maximizing principals' behavior is as follows.

Hypothesis 4 (Principals; Contract Choice) If principals want to maximize their income they will always select the non-monotone contract.

\section{Results of the experiments}

In this section we will first present the analysis of the principals' decisions and then investigate the agents' behavior. If not indicated otherwise, onesided non-parametric tests are used and differences are labeled as significant if $p \leq 0.025$ and are labeled as weakly significant if $0.025<p \leq 0.050$.

\subsection{Principals' behavior}

We observe, over all treatments, that in about 54 percent of all cases principals select the nonmonotone contract $N$. Treatment-specific numbers are given in Table 5 (treatments NFS, FS, FC, $F C R, F C R R)$ and illustrated in Fig.2 (FCR, FCRR), respectively.

Although, theoretically, the non-monotone contract $N$ yields a higher expected payoff than the monotone contract $M$, principals do not choose contract $N$ as often as expected. Applying the binomial test to principals' choices in treatments $N F S, F S$, and $F C$ reveals that principals do not select contract $N$ in a statistically significant way. Similar results can be obtained for principals' choices per matching group for eight of the ten rounds in treatments FCR and FCRR. In both treatments the frequency of choosing $N$ is almost never significantly different from 50 percent (two-tailed, one-sample t-test). This leads to conclusion 1.

\section{Conclusion 1}

In contrast to Hypothesis 4, in all treatments principals do not select the non-monotone contract $N$ in a statistically significant way.

At first sight, one could be tempted to think that principals concerned over agents' behavior at node

\section{Figure 2: Principals' choices in FCR and FCRR}

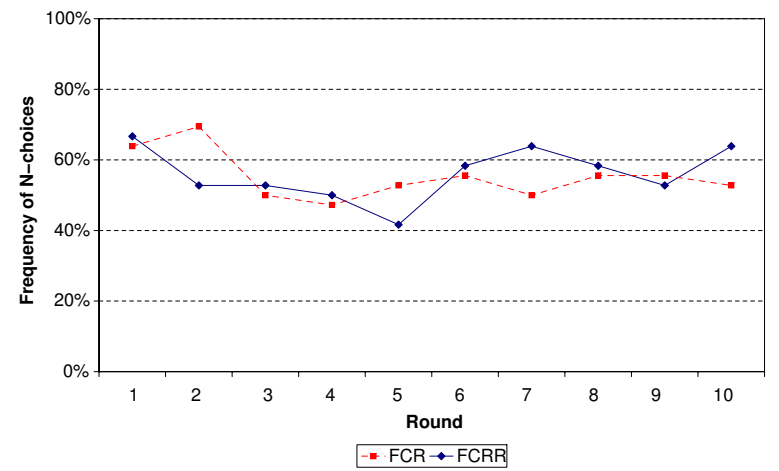

$E_{H}$ might choose $N$ not as often as predicted. At this node, agents' expected payoff from effort is 1.811, and the corresponding expected payoff from 'no effort' amounts to 1.819. (See also the remark on payoff differences in Hypothesis 3.) But even if agents strictly prefer 'no effort' at this node, in terms of expected payoffs principals are still better off with contract $N$ (1.43) compared to $M$ (1.34). It follows that other motives must account for observed principals' behavior.

Another possible explanation is that principals are willing to sacrifice some of their own payoff in order to reduce the inequality between their and the agents' payoff. Recent theoretical and experimental work provide reasons for this assumption (e.g., Fehr and Schmidt 1999; Bolton and Ockenfels 2000; Charness and Rabin 2002). In our setting, however, choosing the monotone contract $M$ instead of the non-monotone contract $N$ even increases the payoff difference according to the theoretical prediction (contract $N$ : principal 1.56 , agent 1.79; contract $M$ : principal 1.35, agent 2.00). Considering agents' actual choices does not change this result for any of the five treatments. In order to get a more detailed picture of principals' behavior, we now turn to an analysis of individual responses in treatments $F C R$ and FCRR, where principals repeatedly decide on a contract. As they can only observe the outcomes of random draws by the computer and the corresponding payments, they do not know the agents' effort choices. Inference from outcomes to action choices is limited to knowing that high payoffs are more likely to result from high effort instead of low effort. To get further insights into individual choices and prefer- 
Table 5: Descriptive data on principals' choices

\begin{tabular}{cccccc} 
& $N F S$ & $F S$ & $F C$ & $F C R$ & $F C R R$ \\
\hline (i) Number of $N$-choices & 11 & 11 & 9 & 199 & 202 \\
\hline (ii) Total number of choices & 20 & 19 & 19 & 360 & 360 \\
\hline Percentage (i) / (ii) & 55.0 & 57.9 & 47.3 & 55.3 & 56.1 \\
\hline
\end{tabular}

Table 6: Descriptive data on principals' individual choices

\begin{tabular}{ccccc} 
& \multicolumn{2}{c}{$F C R$} & \multicolumn{2}{c}{$F C R R$} \\
\hline preference for... & $N$ & $M$ & $N$ & $M$ \\
\hline (i) individual level & 23 & 13 & 23 & 13 \\
\hline (ii) matching group level & 6 & 6 & 7 & 5
\end{tabular}

ences for a contract type we determine the relative frequency of selecting contract $N$ on the individual (or matching group) level. This frequency equals the number of $N$-choices over the total number of rounds. A frequency of at least 0.50 is called a preference for $N$ and a frequency of less than 0.50 is called a preference for $M$. Table 6 summarizes the results.

Though the proportion of matching groups with a preference for $N$ is not significantly different from 50 percent (Binomial test), it is instructive to look at individual data. In both treatments, the 23 individuals with a preference for $N$ account for an average frequency of selecting $N$ of 74 percent, while the 13 individuals with a preference for $M$ show an average frequency of selecting $N$ of just 25 percent (or 75 percent for contract $M$ ). This suggests that participants have a sound understanding of the task documented by frequent repetitions of their decision.

Table 7 illustrates the development of individual contract choices contingent on payoffs realized in the previous round. Since we do not find systematic differences in individual responses between the two contract types, the table aggregates data over both contracts.

In general, we observe a tendency to stay with the contract type chosen in the previous round. This holds true for both events ('winning' and 'losing'). If we find a change of behavior, this is most likely in the case of losing. In treatment $F C R$, particularly, the tendency to stay with the previous contract becomes more pronounced over time. The above findings indicate that principals' behavior is dominated by inertia and additionally guided by a form of the 'Win-Stay-Lose-Change' learning heuristic (cf. Nowak and Sigmund 1993). Over the ten rounds of our experiment, this type of individual 'learning' does not result in a change in aggregate behavior, however.

There are no significant differences in principals' behavior between the treatments. Neither the presence of a statement of the contract type, nor repetition of the decision process by the principal, nor the presence of an opportunity to reject the principals' contract proposal has a significant influence on principal's contract choice.

\subsection{Agents' behavior}

In treatment NFS, there are 11 agents confronted with contract $N$ ( $N$-agents) and 9 agents confronted with contract $M$ ( $M$-agents). In $F S$, the respective numbers are $11 \mathrm{~N}$-agents and $8 \mathrm{M}$-agents and, in treatment $F C$, there are $9 \mathrm{~N}$-agents and 11 $M$-agents. In treatments $F C R / F C R R$, each agent faces contract $N$ on average 5.5/5.6 times and contract $M$ on average 4.5/4.4 times, respectively. The following analysis distinguishes between $N$-agents and $M$-agents. Note that the income-maximizing effort choice in each decision node is identical across contracts due to incentive compatibility. For both contracts, income-maximization calls for high effort in all nodes except $N A_{N}$ and $N A_{H}$. Hypothesis 3 points to a minor specification in node $E_{H}$ under $N$ and $E_{L}$ under $M$.

\section{Income-maximizing behavior}

Our first hypothesis (Hypothesis 1) is related to agents' contract acceptance decisions in treatment FCRR. Of the 183 times that principals offer the (non-monotone) contract $N$, only one offer is rejected; contract $M$ (177 offers) is never rejected by agents. Apparently, agents do not incur the cost to punish the principal's contract choice by decreasing his payoff to $€ 0.50$. Conclusion 2 follows immediately. 
Table 7: Principals' individual responses to observed payoffs

(a) Treatment FCR

\begin{tabular}{clllllllll} 
& \multicolumn{1}{c}{ Response after round } \\
& 1 & 2 & 3 & 4 & 5 & 6 & 7 & 8 & 9 \\
\hline payoff < maximum ('lose') & 0.78 & 0.83 & 0.75 & 0.69 & 0.75 & 0.81 & 0.75 & 0.78 & 0.64 \\
\hline stay with contract & 0.50 & 0.53 & 0.59 & 0.72 & 0.78 & 0.66 & 0.78 & 0.86 & 0.74 \\
\hline change contract & 0.50 & 0.47 & 0.41 & 0.28 & 0.22 & 0.34 & 0.22 & 0.14 & 0.26 \\
\hline payoff = maximum ('win') & 0.22 & 0.17 & 0.25 & 0.31 & 0.25 & 0.19 & 0.25 & 0.22 & 0.36 \\
\hline stay with contract & 0.75 & 0.83 & 1.00 & 0.73 & 0.89 & 1.00 & 1.00 & 1.00 & 0.92 \\
\hline change contract & 0.25 & 0.17 & 0.00 & 0.27 & 0.11 & 0.00 & 0.00 & 0.00 & 0.08 \\
\hline
\end{tabular}

(b) Treatment FCRR

\begin{tabular}{clllllllll} 
& \multicolumn{8}{c}{ Response after round } \\
& 1 & 2 & 3 & 4 & 5 & 6 & 7 & 8 & 9 \\
\hline payoff < maximum ('lose') & 0.72 & 0.78 & 0.81 & 0.81 & 0.89 & 0.83 & 0.61 & 0.83 & 0.81 \\
\hline stay with contract & 0.58 & 0.54 & 0.72 & 0.59 & 0.66 & 0.73 & 0.68 & 0.60 & 0.79 \\
\hline change contract & 0.42 & 0.46 & 0.28 & 0.41 & 0.34 & 0.27 & 0.32 & 0.40 & 0.21 \\
\hline payoff = maximum ('win') & 0.28 & 0.22 & 0.19 & 0.19 & 0.11 & 0.17 & 0.39 & 0.17 & 0.19 \\
\hline stay with contract & 0.80 & 0.88 & 0.57 & 0.86 & 0.75 & 1.00 & 0.79 & 1.00 & 1.00 \\
\hline change contract & 0.20 & 0.12 & 0.43 & 0.14 & 0.25 & 0.00 & 0.21 & 0.00 & 0.00 \\
\hline
\end{tabular}

Table 8: Number of individual agents or matching groups with relative frequency of income-maximizing behavior of at least $50 \%$

\begin{tabular}{lllllllllll} 
Stage & NFS & & $F S$ & & $F C$ & \multicolumn{3}{c}{$F C R$} & \multicolumn{3}{c}{$F C R R$} \\
& $N$ & $M$ & $N$ & $M$ & $N$ & $M$ & $N$ & $M$ & $N$ & $M$ \\
\hline 1 & $8(11)$ & $\underline{9(9)}$ & $\underline{\underline{11(11)}}$ & $\underline{7(8)}$ & $6(9)$ & $8(10)$ & $7(12)$ & $\underline{\underline{12(12)}}$ & $9(12)$ & $\underline{\underline{11(12)}}$ \\
\hline 2 & $3(11)$ & $7(9)$ & $6(11)$ & $\underline{7(8)}$ & $6(9)$ & $\underline{9(10)}$ & $9(12)$ & $\underline{\underline{1(12)}}$ & $9(12)$ & $\underline{\overline{11(12)}}$ \\
\hline $1+2$ & $1(11)$ & $5(9)$ & $3(11)$ & $5(8)$ & $3(9)$ & $8(10)$ & $3(12)$ & $8(12)$ & $3(12)$ & $\overline{7(12)}$ \\
\hline
\end{tabular}

Total number of individual agents or matching groups in parentheses. two underlines: significant ( $p \leq 0.025)$; one underline: weakly significant $(0.025<p \leq 0.050$; Binomial test $)$

\section{Conclusion 2}

In line with Hypothesis 1, in treatment FCRR agents do not reject contract offers.

To obtain a first picture of individual choices (and preferences for effort decisions), we calculate the relative frequency of income-maximizing behavior per contract type on the individual (or matching group) level. This frequency equals the number of rounds exhibiting income-maximizing behavior over the total number of rounds. We call a relative frequency of at least 50 percent a preference for income-maximizing behavior; and of less than 50 percent a preference for non-income-maximizing behavior. Table 8 demonstrates that, on the indi- vidual or group level, there is a pronounced preference for income-maximizing behavior. Apparently, participants gained a sound understanding of the task.

In order to analyze decisions within and between treatments and contracts, we determine the relative frequency of individual income-maximizing decisions per contract type and round (in treatments FCR and FCRR the frequency refers to matching groups). Recall that in these two treatments, principals choose contracts anew in each round and, thus, the number of agents in each matching group facing contract $N$ or $M$ might change over time. Accordingly, we calculated the 
frequency for each matching group based on the actual number of agents facing the respective contract type. The frequencies are obtained as the number of individuals who reveal incomemaximizing behavior over the total number of individuals or as the averages of the twelve matching groups' percentage calculations, respectively. They are illustrated in Figure 3.

Table 9 shows the number of rounds in which we observe a significant majority of subjects (or matching groups) displaying income-maximizing behavior.

\section{Table 9: Number of rounds with at least weakly significant income-maximizing behavior (number of significant cases in parentheses)}

(a) Contract $N$

\begin{tabular}{cccccc} 
Stage & NFS & $F S$ & $F C$ & $F C R$ & FCRR \\
\hline 1 & $1(1)$ & $4(0)$ & o(o) & $3(1)$ & $2(0)$ \\
\hline 2 & o(o) & o(o) & o(o) & $1(1)$ & $3(3)$ \\
$1+2$ & o(o) & o(o) & o(o) & o(o) & o(o)
\end{tabular}

(b) Contract $M$

\begin{tabular}{cccccc} 
Stage & $N F S$ & $F S$ & $F C$ & $F C R$ & $F C R R$ \\
\hline 1 & $3(3)$ & $2(1)$ & o (o) & $7(7)$ & $6(5)$ \\
\hline 2 & $1(1)$ & $3(3)$ & o (o) & $4(3)$ & $5(2)$ \\
\hline $1+2$ & $0(0)$ & $1(0)$ & o(0) & $2(0)$ & $2(1)$ \\
\hline
\end{tabular}

(We applied Binomial tests and t-tests for FCR and $F C R R$, respectively.)

In only 20 percent of all cases (10 rounds out of 10 rounds $\times 5$ treatments) we find significant incomemaximizing behavior for contract $N$ in stage 1 . This number decreases to 8 percent in stage 2. For contract $M$, the respective numbers are 36 percent in stage 1 and 26 percent in stage 2 . This leads to the following conclusions:

\section{Conclusion 3}

In contrast to Hypothesis 2, only a minority of subjects maximizes their income and selects 'effort' in stage 1.

\section{Conclusion 4}

At stage 2, we observe only a small number of subjects behaving in line with Hypothesis 3.

Over the two stages, we do not observe any significant income maximizing behavior for contract $N$, while for contract $M$ in at least 5 of the 50 cases subjects maximize their incomes. This observation led us to analyze possible differences between the two contract types.

\section{Differences between contracts}

Figure 4 displays the average frequency of incomemaximizing decisions over the two stages (stage 1+2) for contracts $N$ and $M$. Applying a twotailed $\chi^{2}$-test on individual data (and a MannWhitney- $U$-test on matching groups) reveals that the monotone contract $M$ performs significantly better (in terms of income-maximization) than the non-monotone contract $N$ in 14 of the 50 cases (10 rounds $\times 5$ treatments). Similar holds true for the single stages, the respective number is 6 for stage 1 and 9 for stage 2. Our observations imply that the maximin-criterion does not provide a complete explanation. To see this, note that for $N$ and $M$, contract rejection yields $€ 0.50$ and contract acceptance (based on the maximin-criterion) yields a payoff of $€ 0.90$. To ensure this payoff, agents must choose 'no effort' in stages 1+2. Given the observed differences in behavior at stages $1+2$, there must be additional influences that guide subjects' behavior here. At stage 2 (ignoring behavior in stage 1), the maximin-criterion and income-maximization coincide for contract $N$, but not for contract $M$. We find an increase of income-maximizing behavior under contract $M$, however, which even contradicts the maximin explanation.

A possible motive for the tendency to withhold effort under contract $N$ might be that agents want to punish the principal for not selecting contract $M$, which is more favorable to them. However, only 6 out of 50 observations provide numbers which are suggestive of such a motive.

Analyzing behavior aggregated over the first five rounds and over the last five rounds reveals a higher share of income-maximizing behavior under the monotone contract $M$ than under the nonmonotone contract $N$ from the first rounds on. This difference in behavior between contracts seems to increase over the rounds.

The previous results might suggest that, from a principal's point of view, contract $M$ is preferable since this contract induces 'effort' somewhat more often than contract $N$ does (see Figure 4 and Table 9). This is not the case, however, as the above result does not carry over to payoffs. In $F S, F C R$, 
Figure 3: Frequencies of income- maximizing agents' behavior Contract N, Stage 1

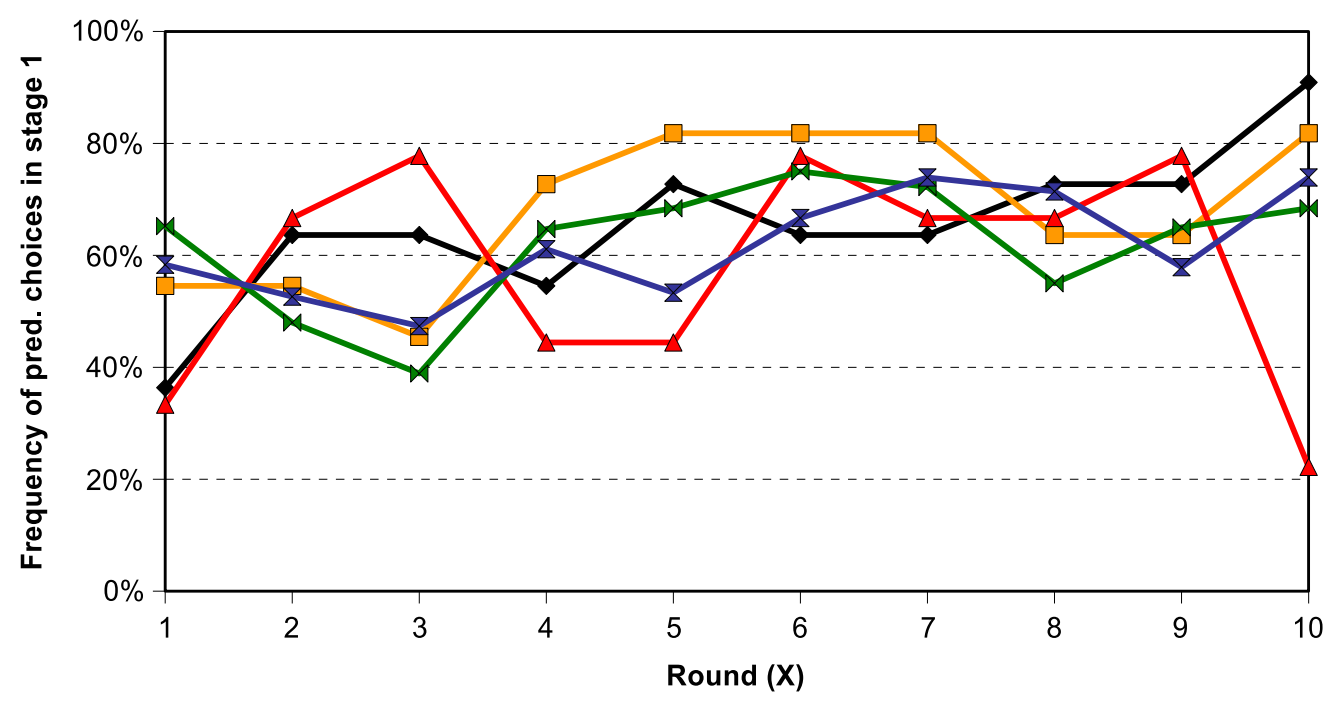

• NFS $\square$ FS $\triangle F C \quad$ FCR $\quad$ F FCRR

Contract M, Stage 1

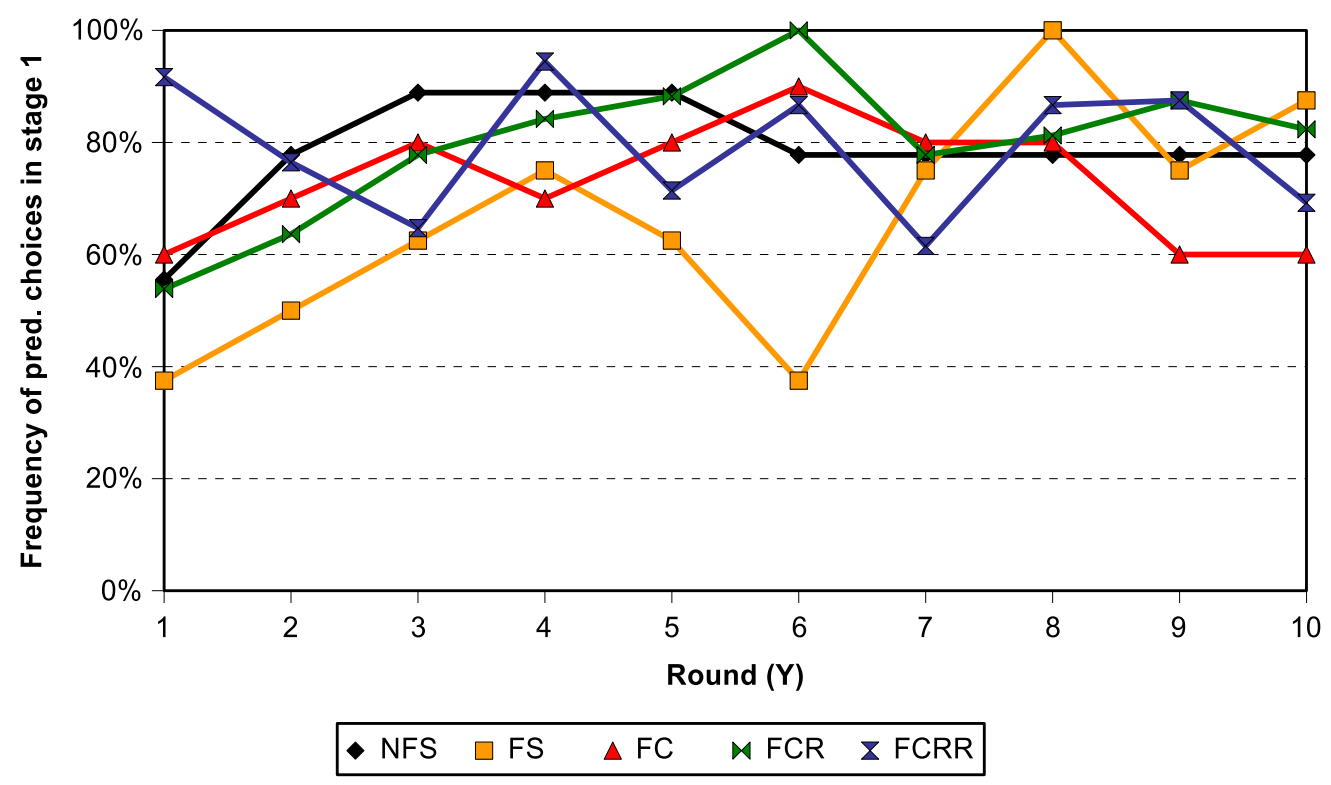


Figure 3 continued: Frequencies of income- maximizing agents' behavior Contract N, Stage 2

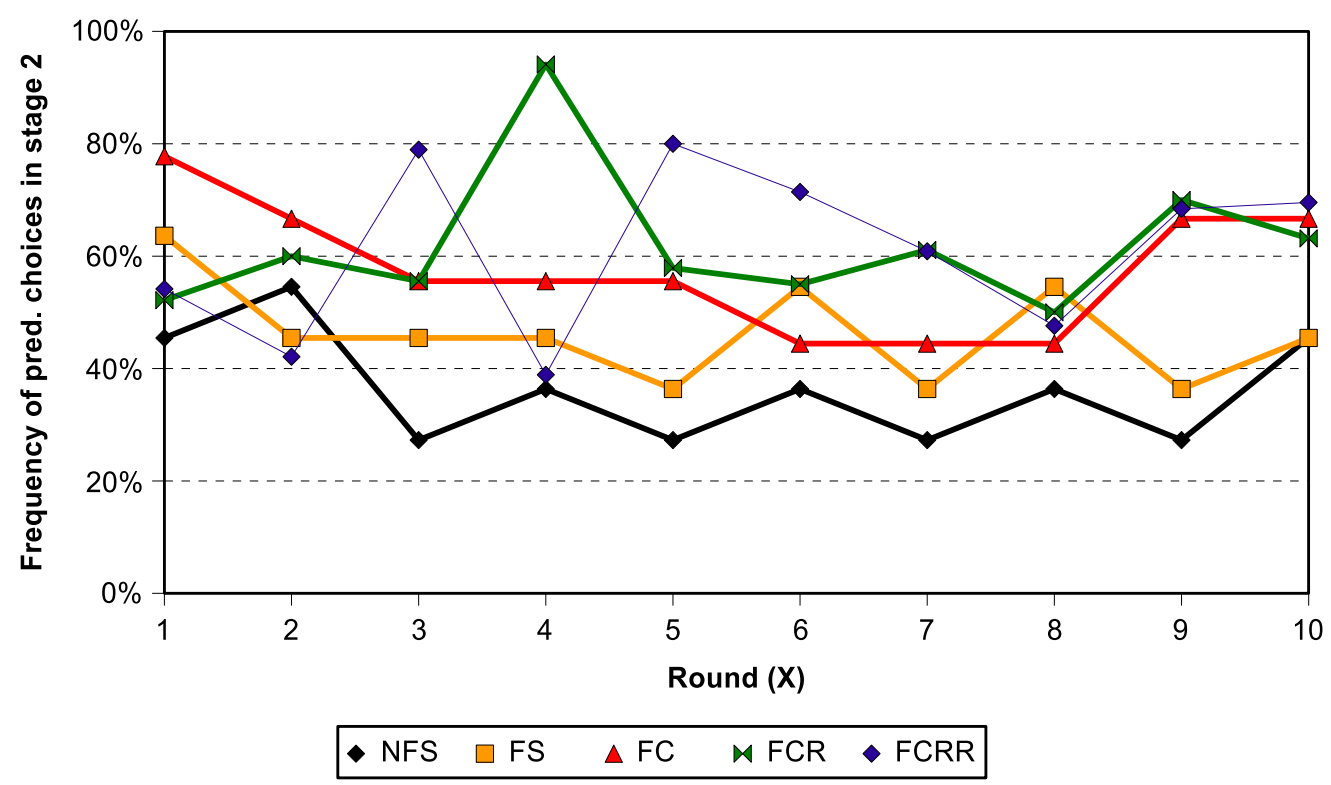

Contract M, Stage 2

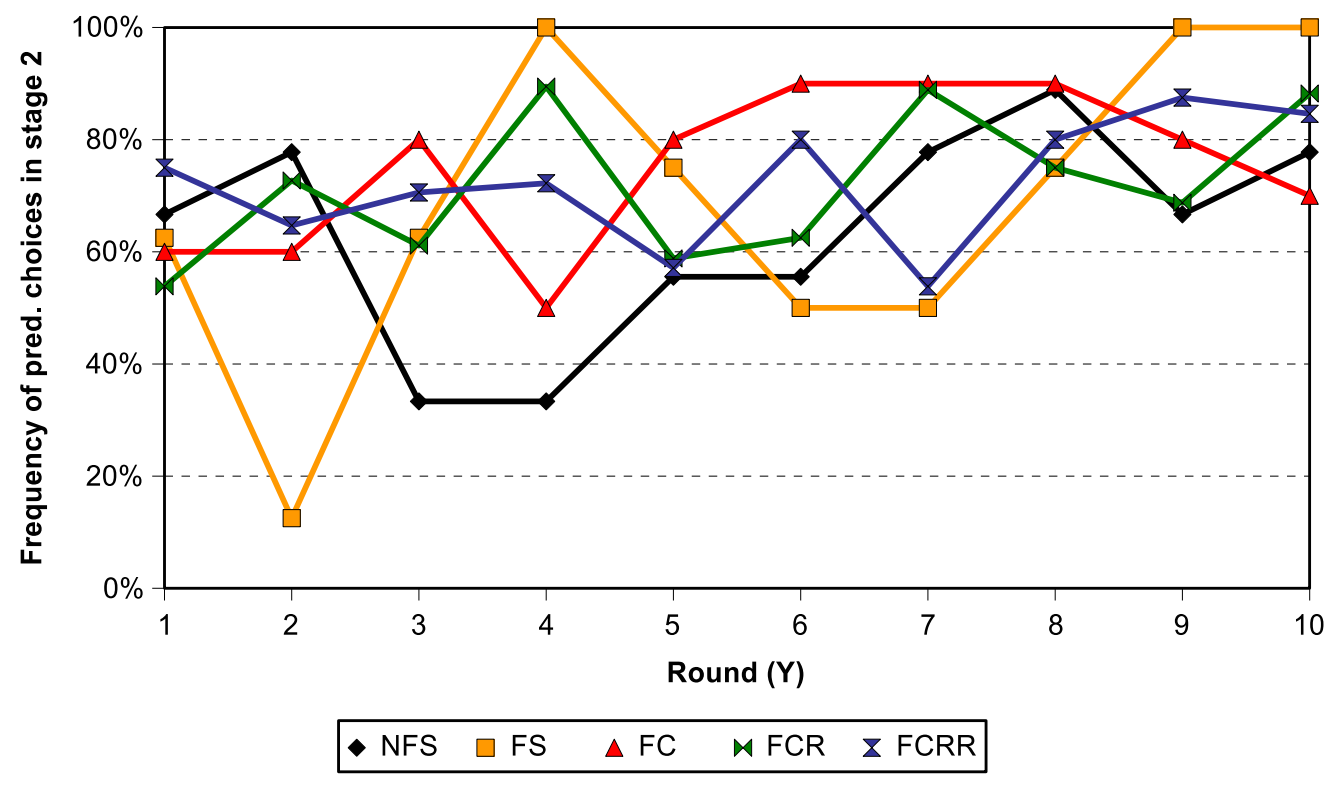


Figure 4: Frequency of income-maximizing decisions for the two contract types in stages $1+2$ in the different treatments

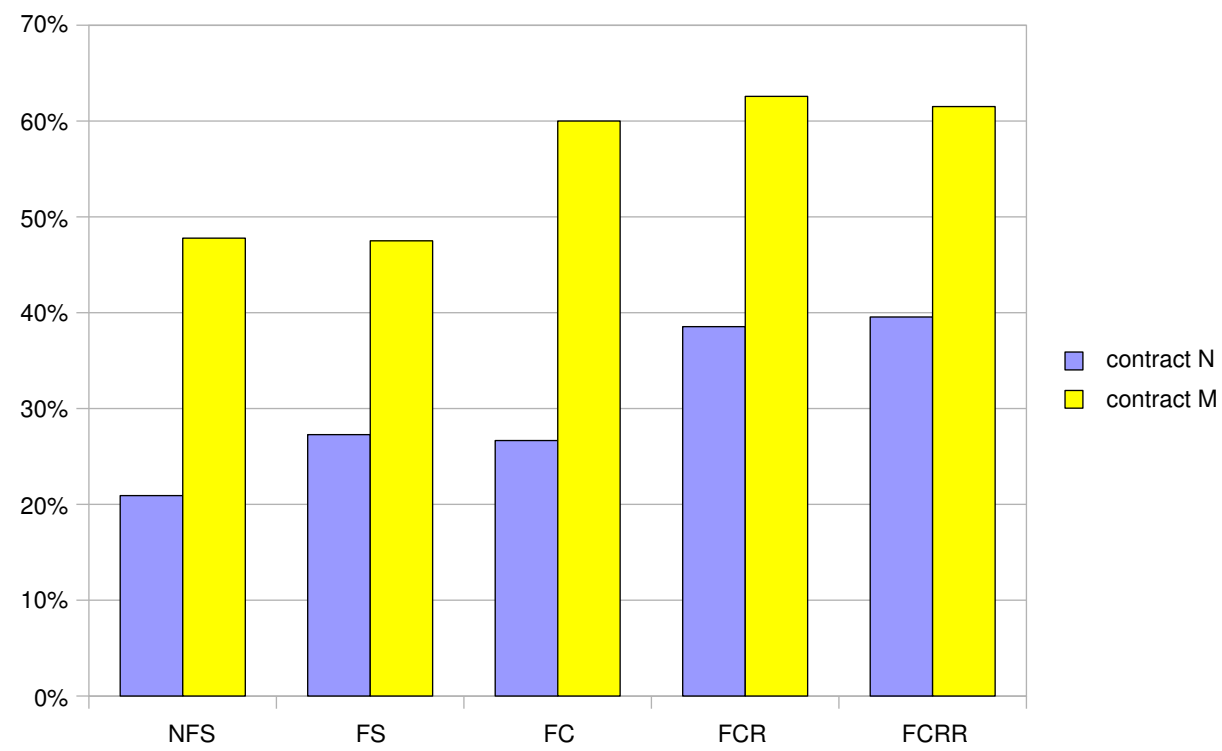

and FCRR, contract $N$ still generates a significantly higher payoff to principals than contract $M$ ( $p<0.07$, two-tailed exact Mann-Whitney-U-test) given observed choices by the agents.

In order to find an explanation for observed agents' decisions, we investigate possible differences between treatments.

\section{Treatment differences}

We find significant differences regarding incomemaximizing behavior at stages $1+2$ for contract $N$ between treatment NFS on the one hand and treatments FCR and FCRR on the other $(p<0.05$, two-tailed exact Mann-Whitney-U-test). In particular, the combination of repetition and complete information significantly increases incomemaximizing behavior. Ceteris paribus, non-monotone contracts perform the better the less often agents (employees) interact with the same principal. Interestingly, this effect is more pronounced in the early rounds of the experiments. This suggests that the effect results from anticipation rather than from experience. More detailed investigations demonstrate that the observed differences in stage$1+2$ behavior are mainly caused by differences in stage-2 behavior. Figure 5 presents the average individual frequency for each treatment and contract type for stage 1 , stage 2 , and stages $1+2$.

What do treatment differences teach us about the appropriateness of non-monotone contracts? First of all, we do not find treatment differences for the monotone contract $M$. This suggests that the awareness of a contract alternative that is inferior from the agents' point of view - the non-monotone contract $N$-does not significantly change their behavior and it does not matter whether they repeatedly interact with different principals or whether they are allowed to reject contract offers. Turning to the non-monotone contract, treatment differences exist between the NFS treatment and both the FCR and FCRR treatment. Note that in the latter two treatments an agent interacts with the same principal less often than in the former treatment. As employment relationships usually feature repeated performance appraisals and corresponding bonus payments, our results imply that nonmonotone contracts are likely to perform worse than monotone ones - given the agent knows that there exists a better contract alternative. As such, our results add some support for the prevalence of monotone contracts.

\section{Conclusion}

Theoretical research in labor economics and contract theory is often restricted to monotone or linear contracts, presumably because of the practical popularity of these types of contract. Such a con- 
Figure 5: Frequency of income maximizing behavior over treatments Stage 1

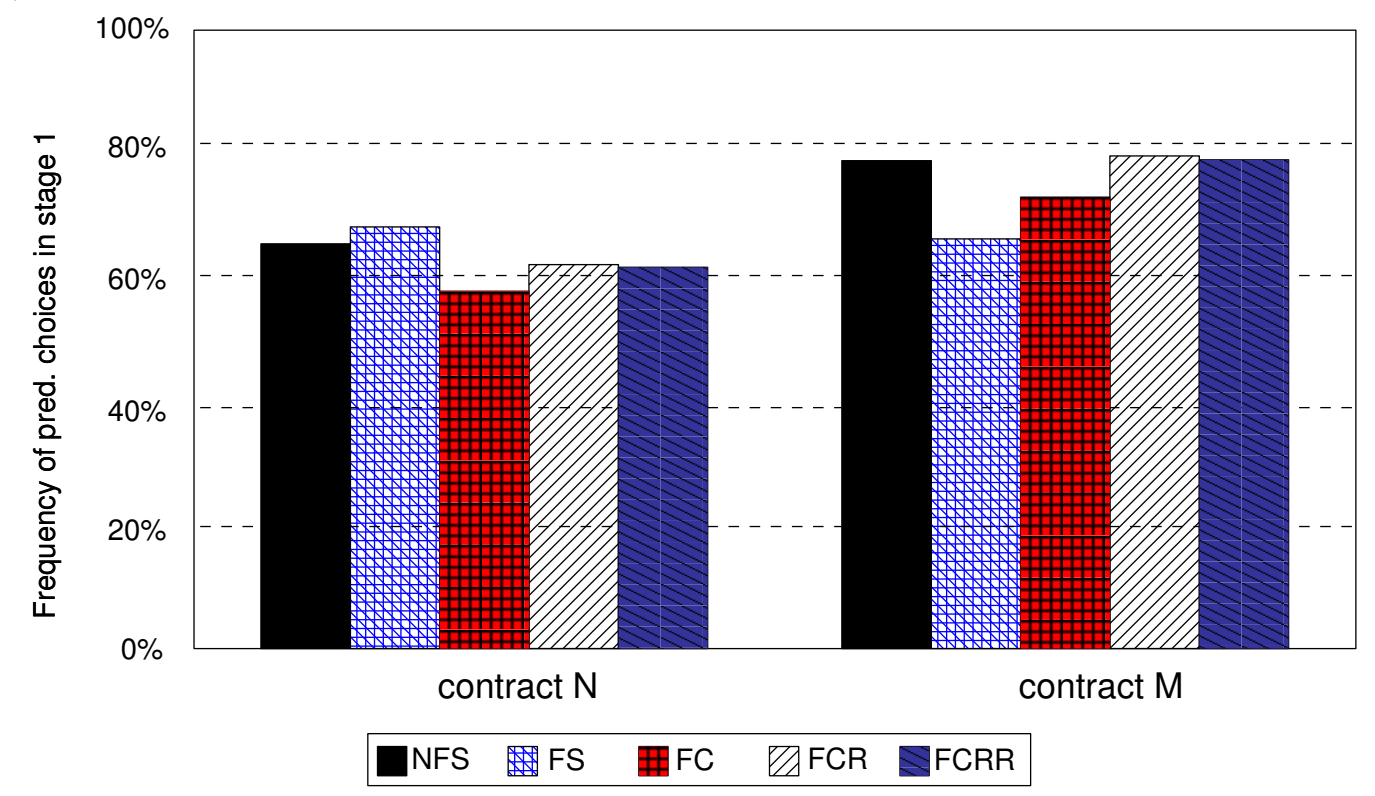

Stage 2

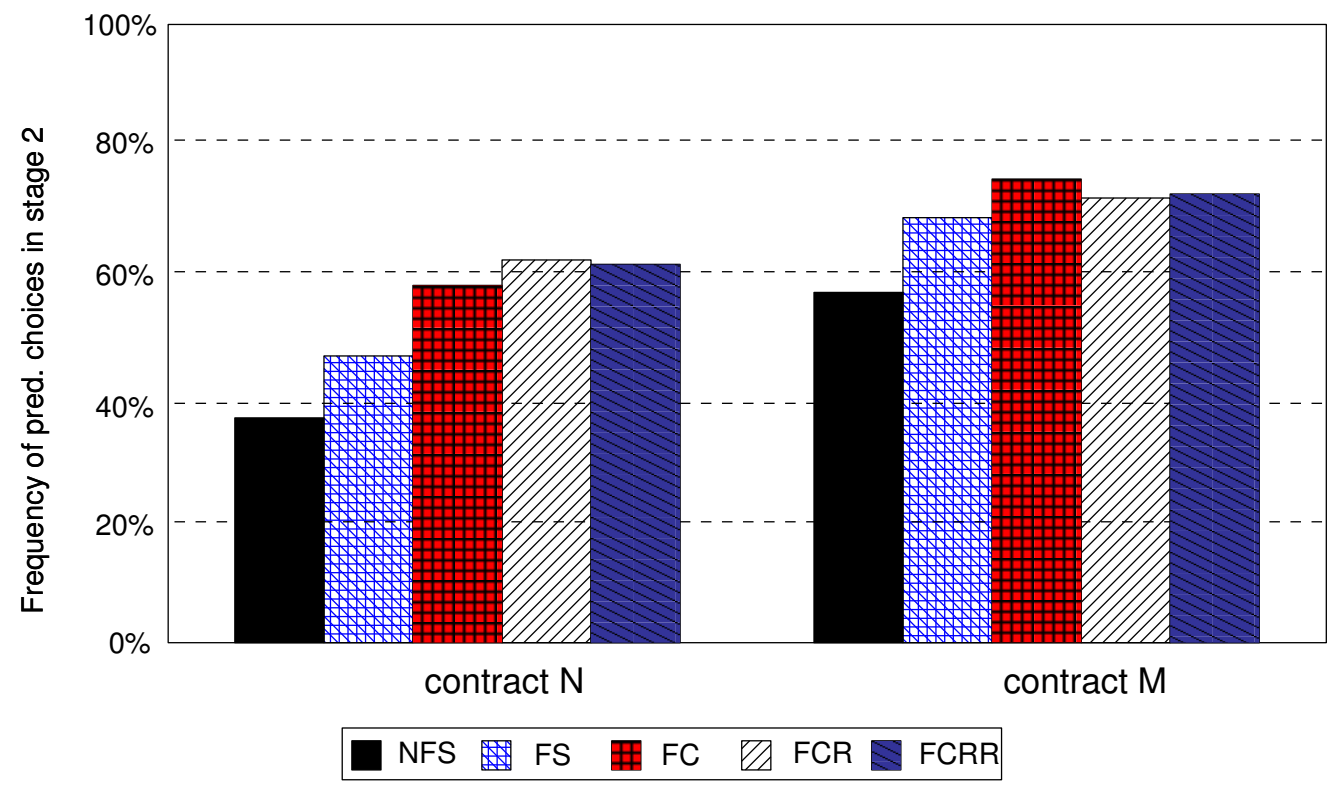


Figure 5 continued: Frequency of income maximizing behavior over treatments

Stages $1+2$

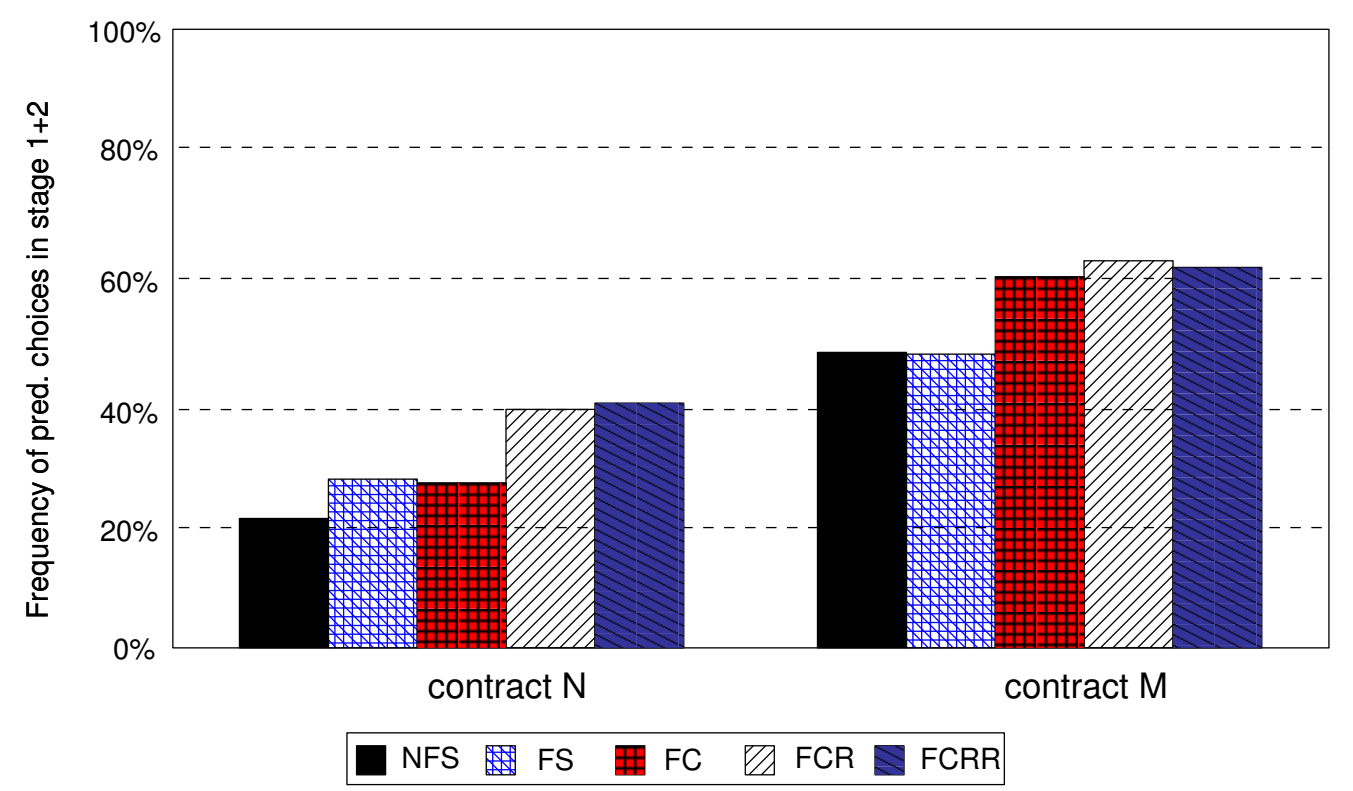

finement, however, neglects the fact that there are cases where non-monotone contracts implement optimal incentive structures, especially if the production technology is non-stationary. Therefore, more insights into the behavioral effects of nonmonotone contracts are needed. Lukas (2007a) provides a first comparison of the performance of monotone and non-monotone contracts under controlled laboratory conditions. The observed principals' preference for non-monotone contracts seems to be not in line with the predominance of monotone contracts in labor market relationships, however. This study is devoted to investigate this monotonicity puzzle in more detail. In particular, we compare incentive-compatible monotone and non-monotone contracts in a setting where principals are predicted to choose the non-monotone one. In contrast to Lukas (2007a), our design includes some features that are not only more natural for employment relationships, but that might also ease the understanding of the incentive structures. With these features, our results reveal more income-maximizing agents under the monotone contract than under the - strategically equivalent - non-monotone contract. However, even with agents' higher efforts under the monotone contract, principals' expected payoffs remain higher under the non-monotone contract. That is, principals are still expected to choose the non-monotone contract. About every second principal chooses the monotone contract, however.

Ruling out different explanations by our treatment design and comparing our data with results from Lukas (2007a), the findings suggest that principals prefer monotonicity because they proxy observable outcomes with unobservable effort which leads them to choose the monotone contract (since here the highest possible output is associated with the highest possible effort). This behavioral pattern would result in a suboptimal design of contracts in cases where incentive-compatibility calls for nonmonotone contracts. Furthermore, even in cases where the theoretically optimal non-monotone contract is chosen, it performs worse when agents have to repeatedly choose their effort for the same principal. Both results might explain why monotone contracts are so popular in real-world labor markets. Based on our findings, future laboratory research might investigate the endogenous design of contracts by giving principals an opportunity to choose certain characteristics of the incentive scheme. This would shed more light on the importance of certain features of the contract design for inducing high effort. Since it turns out that the alternatively available incentive scheme might matter, it is also worthwhile to compare the performance of non-monotone contracts with other means to induce effort like promotion tour- 
naments. Following this line of research requires focusing on more than a single agent and, consequently, taking 'horizontal' equity considerations among agents into account. That these considerations might play a role for behavior under group incentive schemes has been demonstrated by, e.g., Schotter, Bull, and Weigelt (1987) or Nalbantian and Schotter (1997). In particular, if agents tend to compare actual effort-output relations among each other as suggested by, e.g., Abeler, Altmann, Kube, and Wibral (2006) or Gächter and Thöni (2009), this comparison might be more unfavorable under non-monotone contracts. This might be an additional reason for the pre-dominance of monotone contracts in real-world labor markets.

\section{Acknowledgements}

The authors thank Oliver Fabel and two anonymous referees for insightful comments. Financial support by Thurgauer Wirtschaftsinstitut (Thurgau Institute of Economics) under project grant No.81 is gratefully acknowledged.

\section{A Appendix: Instructions}

\section{A.1 Instructions in treatment NFS First-mover instructions}

Welcome to the experiment!

Introduction. You are about to take part in a laboratory experiment to investigate individual behavior in decision-making. During the experiment you participate in 10 repetitions (decision rounds). You can earn money. How much money you will earn depends also on your decisions. After the experiment you will receive your entire payoff in cash.

Please read the following instructions carefully. Approximately five minutes after handing out the instructions we will come to your seat to answer any questions you may have. If you have questions during the experiment, please give us a sign and we will come to your seat.

No participants will receive any information on the identity and decisions of other participants during the experiment.

Situation and decisions. You face the same situation in each of the 10 decision rounds.

You are part of a labor relation that lasts for 2 periods. You are the employer (first-mover). A participant who will be randomly assigned to you is the employee (second-mover). You select one out of two similar contracts $\mathrm{X}$ and $\mathrm{Y}$ that will be effective in all 10 decision rounds. By making your contract choice you decide on the conditions for output-contingent pay that the second-mover receives and at the same time on the conditions for your own payoff.

The second-mover will only be informed about your contract choice (i.e. he will not receive any information on the contract that was not chosen) and then decides whether he expends "effort" or "no effort" in each of the two periods. The probability of achieving a high output will be influenced by the second-mover's effort choice. A higher probability of the high outcome is associated with "effort" than with "no effort". If the second-mover selects "effort" in any period he incurs personal effort costs of $€ 0.45$; "no effort" does not lead to effort costs. The second-mover's first decision in point A determines whether he expends "effort" or "no effort". In case he chooses "no effort" the low outcome and the decision node $N E_{L}$ will be achieved with a probability of $75 \%$. The high outcome and the decision node $N E_{H}$ will be reached with a probability of $25 \%$.

In case the second-mover selects "effort", the low outcome and the decision node $E_{L}$ will be achieved with a probability of $25 \%$. The high outcome and the decision node $E_{H}$ will be reached with a probability of $75 \%$.

The second-mover's first-period decision also affects the outcome probabilities in period 2.

The second-mover's second decision determines whether he expends "effort" of "no effort" if he had achieved the low outcome or the high outcome in period 1. The relevant probabilities and the corresponding net payoffs (personal costs are already deducted) are given in the two decision trees for contract $X$ and contract $Y$, respectively.

Both participants make their decision sequentially. You decide once on the contract, the second-mover decides on his effort twice in each of 10 decision rounds given the contract you selected.

The experiment is carried out on the computer. The computer will determine the results in each period by a random draw with the probabilities as they are given in the decision tree.

Information. After each round the first-mover will be informed about his current round payoff.

After each round the second-mover will be informed about current round outcomes and his 
own payoff.

\section{Second-mover instructions}

Situation and decisions. You face the same situation in each of the 10 decision rounds.

You are part of a labor relation that lasts for 2 periods. A participant who will be randomly assigned to you is the employer (first-mover). You are the employee (second-mover). The first-mover selects one out of two similar contracts $\mathrm{X}$ and $\mathrm{Y}$ that will be effective in all 10 decision rounds. By making his contract choice he decides on the conditions for your output-contingent pay and at the same time on the conditions of his own payoff.

You will only be informed about the contract chosen (i.e. you will not receive any information on the contract that was not chosen) and then you decide whether you expend "effort" or "no effort" in each of the two periods. The probability of achieving a high output will be influenced by the your effort choice. A higher probability of the high outcome is associated with "effort" than with "no effort". If you select "effort" in any period you incur personal effort costs of $€ 0.45$; "no effort" does not lead to effort costs.

Your first decision in point A determines whether you expend "effort" or "no effort". In case you choose "no effort" the low outcome and the decision node $N E_{L}$ will be achieved with a probability of $75 \%$. The high outcome and the decision node $N E_{H}$ will be reached with a probability of $25 \%$.

In case you select "effort", the low outcome and the decision node $E_{L}$ will be achieved with a probability of $25 \%$. The high outcome and the decision node $E_{H}$ will be reached with a probability of $75 \%$.

Your first-period decision also affects the outcome probabilities in period 2.

Your second decision determines whether you expend "effort" of "no effort" if you had achieved the low outcome or the high outcome in period 1. The relevant probabilities and the corresponding net payoffs (personal costs are already deducted) are given in the decision tree.

Both participants make their decision sequentially. The first-mover decides once on the contract, you decide on your effort twice in each of 10 decision rounds given the contract selected by the firstmover.

The experiment is carried out on the computer. The computer will determine the results in each period by a random draw with the probabilities as they are given in the decision tree.

Information. After each round the first-mover will be informed about his current round payoff.

After each round the second-mover will be informed about current round outcomes and his own payoff.

\section{A.2 Treatment FS \\ First-mover instructions}

Welcome to the experiment!

Introduction. You are about to take part in a laboratory experiment to investigate individual behavior in decision-making. During the experiment you participate in 10 repetitions (decision rounds). You can earn money. How much money you will earn depends on your decisions. After the experiment you will receive your entire payoff in cash.

Please read the following instructions carefully. Approximately five minutes after handing out the instructions we will come to your seat to answer any questions you may have. If you have questions during the experiment, please give us a sign and we will come to your seat.

No participants will receive any information on the identity and decisions of other participants during the experiment.

Situation and decisions. You face the same situation in each of the 10 decision rounds.

You are part of a labor relation that lasts for 2 periods. You are the employer (first-mover). A participant who will be randomly assigned to you is the employee (second-mover). You choose between two similar contracts $\mathrm{X}$ and $\mathrm{Y}$ that will be effective in all 10 decision rounds. Your choice determines the conditions for output-contingent pay that the second-mover receives and at the same time on the conditions for your own payoff.

The second-mover will only be informed about your contract choice (i.e. he will not receive any information on the contract that was not chosen) and then decides whether he expends "effort" or "no effort" in each of the two periods. The probability of achieving a high output will be influenced by the second-mover's effort choice. A higher probability of the high outcome is associated with "effort" than with "no effort". If the second-mover selects "effort" in any period he incurs personal effort costs of $€ 0.45$; "no effort" does not lead to effort costs. The second-mover's first decision in point A deter- 
mines whether he expends "effort" or "no effort". In case he chooses "no effort" the low outcome and the decision node $N E_{L}$ will be achieved with a probability of $60 \%$. The high outcome and the decision node $N E_{H}$ will be reached with a probability of $40 \%$.

In case the second-mover selects "effort", the low outcome and the decision node $E_{L}$ will be achieved with a probability of $20 \%$. The high outcome and the decision node $E_{H}$ will be reached with a probability of $80 \%$.

The second-mover's first-period decision also affects the outcome probabilities in period 2.

The second-mover's second decision determines whether he expends "effort" of "no effort" if he had achieved the low outcome or the high outcome in period 1 . The relevant probabilities and the corresponding net payoffs (personal costs are already deducted) are given in the two decision trees for contract $\mathrm{X}$ and contract $\mathrm{Y}$, respectively.

Both participants make their decision sequentially. You decide once on the contract, the second mover decides on his effort twice in each of 10 decision rounds given the contract you selected.

Contract $\mathrm{X}$ is characterized by the fact that the output-contingent pay of the second mover does not rise monotonously in the output-level, i.e. the outcome sequence $\{$ low; high $\}$ leads to a higher payment than the output sequence $\{$ high; high\} for every possible combination of effort levels. Contract $\mathrm{Y}$, on the other hand, is characterized by the fact that the outcome sequence $\{$ low; high $\}$ leads to a lower payment than the output sequence $\{$ high; high\} for every possible combination of effort levels.

The following examples will clarify this:

\begin{tabular}{cccc} 
Effort & $\begin{array}{c}\text { Outcome } \\
\text { sequence }\end{array}$ & $\begin{array}{r}\text { net paym. } \\
\text { 2nd mov. } \\
\text { cont. X }\end{array}$ & $\begin{array}{c}\text { net paym. } \\
\text { 2nd mov. } \\
\text { cont. Y }\end{array}$ \\
\hline \{yes; yes\} & $\{$ low; high\} & 2.5 & 2.1 \\
\hline \{yes; yes & $\{$ high; high $\}$ & 2.1 & 2.5 \\
\hline nno; no $\}$ & $\{$ low; high $\}$ & 3.4 & 3 \\
\hline nno; no $\}$ & $\{$ high; high & 3 & 3.4 \\
\hline
\end{tabular}

The experiment is carried out on the computer. The computer will determine the results in each period by a random draw with the probabilities as they are given in the decision tree.

Information. After each round the first-mover will be informed about his current round payoff.
After each round the second-mover will be informed about current round outcomes and his own payoff.

Payoff. With the completion of the 10 decision rounds you will receive the sum of your payments of every round in cash.

\section{Second-mover instructions}

Welcome to the experiment!

Introduction. You are about to take part in a laboratory experiment to investigate individual behavior in decision making. During the experiment you participate in 10 repetitions (decision rounds). You can earn money. How much money you will earn depends on your decisions. After the experiment you will receive your entire payoff in cash.

Please read the following instructions carefully. Approximately five minutes after handing out the instructions we will come to your seat to answer any questions you may have. If you have questions during the experiment, please give us a sign and we will come to your seat.

No participants will receive any information on the identity and decisions of other participants during the experiment.

Situation and decisions. You face the same situation in each of the 10 decision rounds.

You are part of a labor relation that lasts for 2 periods. A participant who will be randomly assigned to you is the employer (first-mover). You are the employee (second-mover). The first-mover selects one out of two similar contracts $\mathrm{X}$ and $\mathrm{Y}$ that will be effective in all 10 decision rounds. By making his contract choice he decides on the conditions for your output-contingent pay and at the same time on the conditions of his own payoff.

You will only be informed about the chosen contract (i.e. you will not receive any information on the contract that was not chosen) and then you decide whether you expend "effort" or "no effort" in each of the two periods. The probability of achieving a high output will be influenced by your effort choice. A higher probability of the high outcome is associated with "effort" than with "no effort". If you select "effort" in any period you incur personal effort costs of $€ 0.45$; "no effort" does not lead to effort costs.

Your first decision in point A determines whether you expend "effort" or "no effort". In case you choose "no effort" the low outcome and the deci- 
sion node $N E_{L}$ will be achieved with a probability of $60 \%$. The high outcome and the decision node $N E_{H}$ will be reached with a probability of $40 \%$. In case you select "effort", the low outcome and the decision node $E_{L}$ will be achieved with a probability of $20 \%$. The high outcome and the decision node $E_{H}$ will be reached with a probability of $80 \%$. Your first-period decision also affects the outcome probabilities in period 2.

Your second decision determines whether you expend "effort" or "no effort" if you had achieved the low outcome or the high outcome in period 1 . The relevant probabilities and the corresponding net payoffs (personal costs are already deducted) are given in the decision tree.

Both participants make their decision sequentially. The first-mover decides once on the contract, you decide on your effort twice in each of 10 decision rounds given the contract selected by the firstmover.

The experiment is carried out on the computer. The computer will determine the results in each period by a random draw with the probabilities as they are given in the decision tree.

Information. After each round the first-mover will be informed about his current round payoff.

After each round the second-mover will be informed about current round outcomes and his own payoff.

Payoff. With the completion of the 10 decision rounds you will receive the sum of your payments of every round in cash.

The following information was given to participants if the principal selected contract $X$ or contract $Y$, respectively.

\section{Contract X.}

Contract $\mathrm{X}$, which is chosen by the first mover, is characterized by the fact that the output-contingent pay of the second mover does not rise monotonously in the output-level, i.e. the outcome sequence \{low; high leads to a higher payment than the output sequence $\{$ high; high $\}$ for every possible combination of effort levels.
The following examples will clarify this:

\begin{tabular}{|c|c|c|}
\hline $\begin{array}{l}\text { Effort } \\
\text { yes/no }\end{array}$ & $\begin{array}{l}\text { Outcome } \\
\text { sequence }\end{array}$ & $\begin{array}{l}\text { net payment for } \\
\text { second mover } \\
\text { with contract } \mathrm{X}\end{array}$ \\
\hline$\{$ yes; yes\} & \{low; high\} & 2.5 \\
\hline$\{$ yes; yes\} & $\{$ high; high $\}$ & 2.1 \\
\hline$\{$ no; no $\}$ & $\{$ low; high\} & 3.4 \\
\hline$\{$ no; no $\}$ & $\{$ high; high $\}$ & 3 \\
\hline
\end{tabular}

\section{Contract Y.}

Contract $\mathrm{Y}$ is characterized by the fact that the outcome sequence $\{$ low; high $\}$ leads to a lower payment than the output sequence $\{$ high; high $\}$ for every possible combination of effort levels.

The following examples will clarify this:

\begin{tabular}{|c|c|c|}
\hline $\begin{array}{l}\text { Effort } \\
\text { yes/no }\end{array}$ & $\begin{array}{l}\text { Outcome } \\
\text { sequence }\end{array}$ & $\begin{array}{l}\text { net payment for } \\
\text { second mover } \\
\text { with contract } Y\end{array}$ \\
\hline$\{$ yes; yes\} & \{low; high\} & 2.1 \\
\hline \{yes; yes\} & $\{$ high; high\} & 2.5 \\
\hline$\{$ no; no $\}$ & \{low; high\} & 3 \\
\hline$\{$ no; no $\}$ & $\{$ high; high\} & 3.4 \\
\hline
\end{tabular}

\section{A.3 Treatment FC First-mover instructions}

Introduction. You are about to take part in a laboratory experiment to investigate individual behavior in decision making. During the experiment you participate in 10 repetitions (decision rounds). You can earn money. How much money you will earn depends on your decisions. After the experiment you will receive your entire payoff in cash.

Please read the following instructions carefully. Approximately five minutes after handing out the instructions we will come to your seat to answer any questions you may have. If you have questions during the experiment, please give us a sign and we will come to your seat.

No participants will receive any information on the identity and decisions of other participants during the experiment.

Situation and decisions. You face the same situation in each of the 10 decision rounds.

You are part of a labor relation that lasts for 2 periods. You are the employer (first-mover). A participant who will be randomly assigned to you is the employee (second-mover). You choose between 
two similar contracts $\mathrm{X}$ and $\mathrm{Y}$ that will be effective in all 10 decision rounds. Your choice determines the conditions for output-contingent pay that the second-mover receives and at the same time on the conditions for your own payoff.

The second-mover will be informed about your contract choice and about the contract you have not chosen (i.e. he will receive all information on each possible contracts) and then decides whether he expends "effort" or "no effort" in each of the two periods. The probability of achieving a high output will be influenced by the second-mover's effort choice. A higher probability of the high outcome is associated with "effort" than with "no effort". If the second-mover selects "effort" in any period he incurs personal effort costs of $€ 0.45$; "no effort" does not lead to effort costs.

The second-mover's first decision in point A determines whether he expends "effort" or "no effort". In case he chooses "no effort" the low outcome and the decision node $N E_{L}$ will be achieved with a probability of $60 \%$. The high outcome and the decision node $N E_{H}$ will be reached with a probability of $40 \%$.

In case the second-mover selects "effort", the low outcome and the decision node $E_{L}$ will be achieved with a probability of $20 \%$. The high outcome and the decision node $E_{H}$ will be reached with a probability of $80 \%$.

The second-mover's first-period decision also affects the outcome probabilities in period 2.

The second-mover's second decision determines whether he expends "effort" of "no effort" if he had achieved the low outcome or the high outcome in period 1. The relevant probabilities and the corresponding net payoffs (personal costs are already deducted) are given in the two decision trees for contract $\mathrm{X}$ and contract $\mathrm{Y}$, respectively.

Both participants make their decision sequentially. You decide once on the contract, the second mover decides on his effort twice in each of 10 decision rounds given the information about both possible contracts.

Contract $\mathrm{X}$ is characterized by the fact that the output-contingent pay of the second mover does not rise monotonously in the output-level, i.e. the outcome sequence $\{$ low; high $\}$ leads to a higher payment than the output sequence $\{$ high; high $\}$ for every possible combination of effort levels. Contract $\mathrm{Y}$, on the other hand, is characterized by the fact that the outcome sequence $\{$ low; high $\}$ leads to a lower payment than the output sequence $\{$ high; high\} for every possible combination of effort levels.

The following examples will clarify this:

(Remark: The second-mover will get the same table of contract information.)

\begin{tabular}{cccc} 
Effort & $\begin{array}{c}\text { Outcome } \\
\text { sequence }\end{array}$ & $\begin{array}{c}\text { net paym. } \\
\text { 2nd mover } \\
\text { w. cont. X }\end{array}$ & $\begin{array}{c}\text { net paym. } \\
\text { 2nd mover } \\
\text { w. cont. Y }\end{array}$ \\
\hline yyes; yes\} & $\{$ low; high\} & 2.5 & 2.1 \\
\hline yes; yes\} & $\{$ high; high & 2.1 & 2.5 \\
\hline nno; no & $\{$ low; high & 3.4 & 3 \\
\hline nno; no & $\{$ high; high & 3 & 3.4 \\
\hline
\end{tabular}

The experiment is carried out on the computer. The computer will determine the results in each period by a random draw with the probabilities as they are given in the decision tree.

Information. After each round the first-mover will be informed about his current round payoff.

After each round the second-mover will be informed about current round outcomes and his own payoff.

Payoff. With the completion of the 10 decision rounds you will receive the sum of your payments of every round in cash.

\section{Second-mover instructions}

Welcome to the experiment!

Introduction. You are about to take part in a laboratory experiment to investigate individual behavior in decision making. During the experiment you participate in 10 repetitions (decision rounds). You can earn money. How much money you will earn depends on your decisions. After the experiment you will receive your entire payoff in cash.

Please read the following instructions carefully. Approximately five minutes after handing out the instructions we will come to your seat to answer any questions you may have. If you have questions during the experiment, please give us a sign and we will come to your seat.

No participants will receive any information on the identity and decisions of other participants during the experiment.

Situation and decisions: You face the same situation in each of the 10 decision rounds.

You are part of a labor relation that lasts for 2 periods. A participant who will be randomly assigned to you is the employer (first-mover). You are the 
employee (second-mover). The first-mover selects one out of two similar contracts $\mathrm{X}$ and $\mathrm{Y}$ that will be effective in all 10 decision rounds. By making his contract choice he decides on the conditions for your output-contingent pay and at the same time on the conditions of his own payoff.

You will be informed about the chosen contract and about the contract that was not chosen (i.e. you will get all information about each possible contract). Then you decide whether you expend "effort" or "no effort" in each of the two periods. The probability of achieving a high output will be influenced by your effort choice. A higher probability of the high outcome is associated with "effort" than with "no effort". If you select "effort" in any period you incur personal effort costs of $€ 0.45$; "no effort" does not lead to effort costs.

Your first decision in point A determines whether you expend "effort" or "no effort". In case you choose "no effort" the low outcome and the decision node $N E_{L}$ will be achieved with a probability of $60 \%$. The high outcome and the decision node $N E_{H}$ will be reached with a probability of $40 \%$. In case you select "effort", the low outcome and the decision node $E_{L}$ will be achieved with a probability of $20 \%$. The high outcome and the decision node $E_{H}$ will be reached with a probability of $80 \%$. Your first-period decision also affects the outcome probabilities in period 2.

Your second decision determines whether you expend "effort" or "no effort" if you had achieved the low outcome or the high outcome in period 1 . The relevant probabilities and the corresponding net payoffs (personal costs are already deducted) are given in the decision tree.

Both participants make their decision sequentially. The first-mover decides once on the contract, you decide on your effort twice in each of 10 decision rounds given the contract selected by the firstmover.

Contract $\mathrm{X}$ is characterized by the fact that the output-contingent pay of the second mover does not rise monotonously in the output-level, i.e. the outcome sequence \{low; high $\}$ leads to a higher payment than the output sequence $\{$ high; high\} for every possible combination of effort levels. Contract $\mathrm{Y}$, on the other hand, is characterized by the fact that the outcome sequence $\{$ low; high $\}$ leads to a lower payment than the output sequence $\{$ high; high\} for every possible combination of effort levels.
The following examples will clarify this:

\begin{tabular}{cccc} 
Effort & $\begin{array}{c}\text { Outcome } \\
\text { sequence }\end{array}$ & $\begin{array}{c}\text { net paym. } \\
\text { 2nd mover } \\
\text { w. cont. X }\end{array}$ & $\begin{array}{c}\text { net paym. } \\
\text { 2nd mover } \\
\text { w. cont. Y }\end{array}$ \\
\hline yyes; yes $\}$ & $\{$ low; high\} & 2.5 & 2.1 \\
\hline yes; yes\} & $\{$ high; high & 2.1 & 2.5 \\
\hline nno; no & $\{$ low; high & 3.4 & 3 \\
\hline nno; no & $\{$ high; high & 3 & 3.4 \\
\hline
\end{tabular}

The experiment is carried out on the computer. The computer will determine the results in each period by a random draw with the probabilities as they are given in the decision tree.

Information. After each round the first-mover will be informed about his current round payoff.

After each round the second-mover will be informed about current round outcomes and his own payoff.

Payoff. With the completion of the 10 decision rounds you will receive the sum of your payments of every round in cash.

\section{A.4 Treatment FCR \\ First-mover instructions}

Welcome to the experiment!

Introduction. You are about to take part in a laboratory experiment to investigate individual behavior in decision making. During the experiment you participate in 10 repetitions (decision rounds). You can earn money. How much money you will earn depends on your decisions. After the experiment you will receive your entire payoff in cash.

Please read the following instructions carefully. Approximately five minutes after handing out the instructions we will come to your seat to answer any questions you may have. If you have questions during the experiment, please give us a sign and we will come to your seat.

No participants will receive any information on the identity and decisions of other participants during the experiment.

Situation and decisions. You face the same situation in each of the 10 decision rounds.

You are part of a labor relation that lasts for 2 periods. You are the employer (first-mover). In each decision round a participant will be randomly assigned to you. He is the employee (second-mover). At the beginning of each decision round you choose between two similar contracts X and Y. Your choice 
determines the conditions for output-contingent pay that the second-mover receives and at the same time on the conditions for your own payoff. The second-mover will be informed about your contract choice and about the contract you have not chosen (i.e. he will receive all information on each possible contracts) and then decides whether he expends "effort" or "no effort" in each of the two periods. The probability of achieving a high output will be influenced by the second-mover's effort choice. A higher probability of the high outcome is associated with "effort" than with "no effort". If the second-mover selects "effort" in any period he incurs personal effort costs of $€ 0.45$; "no effort" does not lead to effort costs.

The second-mover's first decision in point A determines whether he expends "effort" or "no effort". In case he chooses "no effort" the low outcome and the decision node $N E_{L}$ will be achieved with a probability of $60 \%$. The high outcome and the decision node $N E_{H}$ will be reached with a probability of $40 \%$.

In case the second-mover selects "effort", the low outcome and the decision node $E_{L}$ will be achieved with a probability of $20 \%$. The high outcome and the decision node $E_{H}$ will be reached with a probability of $80 \%$.

The second-mover's first-period decision also affects the outcome probabilities in period 2.

The second-mover's second decision determines whether he expends "effort" or "no effort" if he had achieved the low outcome or the high outcome in period 1 . The relevant probabilities and the corresponding net payoffs (personal costs are already deducted) are given in the two decision trees for contract $\mathrm{X}$ and contract $\mathrm{Y}$, respectively.

Both participants make their decision sequentially. First you decide on the contract, the second-mover then will decide on his effort twice knowing both contract types which were available. This sequence will be the same in each of the 10 decision rounds. Contract $\mathrm{X}$ is characterized by the fact that the output-contingent pay of the second mover does not rise monotonously in the output-level, i.e. the outcome sequence \{low; high \} leads to a higher payment than the output sequence $\{$ high; high $\}$ for every possible combination of effort levels. Contract $\mathrm{Y}$, on the other hand, is characterized by the fact that the outcome sequence $\{$ low; high\} leads to a lower payment than the output sequence $\{$ high; high\} for every possible combination of effort le- vels.

The following examples will clarify this:

\begin{tabular}{cccc} 
Effort & $\begin{array}{c}\text { Outcome } \\
\text { sequence }\end{array}$ & $\begin{array}{c}\text { net paym. } \\
\text { 2nd mover } \\
\text { w. cont } \mathrm{X}\end{array}$ & $\begin{array}{c}\text { net paym. } \\
\text { 2nd mover } \\
\text { w cont Y }\end{array}$ \\
\hline yyes; yes $\}$ & $\{$ low; high\} & 2.5 & 2.1 \\
\hline yes; yes $\}$ & $\{$ high; high & 2.1 & 2.5 \\
\hline nno; no & $\{$ low; high & 3.4 & 3 \\
\hline nno; no & $\{$ high; high & 3 & 3.4 \\
\hline
\end{tabular}

The experiment is carried out on the computer. The computer will determine the results in each period by a random draw with the probabilities as they are given in the decision tree.

Information. After each round the first-mover will be informed about his current round payoff.

After each round the second-mover will be informed about current round outcomes and his own payoff.

Payoff. With the completion of the 10 decision rounds you will receive the sum of your payments of every round in cash.

\section{Second-mover instructions}

Welcome to the experiment!

Introduction. You are about to take part in a laboratory experiment to investigate individual behavior in decision making. During the experiment you participate in 10 repetitions (decision rounds). You can earn money. How much money you will earn depends on your decisions. After the experiment you will receive your entire payoff in cash.

Please read the following instructions carefully. Approximately five minutes after handing out the instructions we will come to your seat to answer any questions you may have. If you have questions during the experiment, please give us a sign and we will come to your seat.

No participants will receive any information on the identity and decisions of other participants during the experiment.

Situation and decisions. You face the same situation in each of the 10 decision rounds.

You are part of a labor relation that lasts for 2 periods. In each decision round a participant will be randomly assigned to you. He is the employer (first-mover) and you are the employee (secondmover). The first-mover selects one out of two similar contracts $\mathrm{X}$ and $\mathrm{Y}$ that will only be effective in this decision round. By making his con- 
tract choice he decides on the conditions for your output-contingent pay and at the same time on the conditions of his own payoff.

You will be informed about the chosen contract and about the contract that was not chosen (i.e. you will get all information about each possible contract). Then you have to decide whether you expend "effort" or "no effort" in each of the two periods. The probability of achieving a high output will be influenced by your effort choice. A higher probability of the high outcome is associated with "effort" than with "no effort". If the second-mover selects "effort" in any period he incurs personal effort costs of $€ 0.45$; "no effort" does not lead to effort costs. Your first decision in point A determines whether you expend "effort" or "no effort". In case you choose "no effort" the low outcome and the decision node $N E_{L}$ will be achieved with a probability of $60 \%$. The high outcome and the decision node $N E_{H}$ will be reached with a probability of $40 \%$. In case you select "effort", the low outcome and the decision node $E_{L}$ will be achieved with a probability of $20 \%$. The high outcome and the decision node $E_{H}$ will be reached with a probability of $80 \%$. Your first-period decision also affects the outcome probabilities in period 2.

Your second decision determines whether you expend "effort" or "no effort" if you had achieved the low outcome or the high outcome in period 1 . The relevant probabilities and the corresponding net payoffs (personal costs are already deducted) are given in the decision tree.

Both participants make their decision sequentially. The first-mover chooses the contract, then you decide on your effort twice knowing both contract types which were available. This sequence will be the same in each of the 10 decision rounds.

Contract $\mathrm{X}$ is characterized by the fact that the output-contingent pay of the second mover does not rise monotonously in the output-level, i.e. the outcome sequence $\{$ low; high $\}$ leads to a higher payment than the output sequence $\{$ high; high $\}$ for every possible combination of effort levels. Contract $\mathrm{Y}$, on the other hand, is characterized by the fact that the outcome sequence \{low; high\} leads to a lower payment than the output sequence $\{$ high; high\} for every possible combination of effort levels.
The following examples will clarify this:

\begin{tabular}{cccc} 
Effort & $\begin{array}{c}\text { Outcome } \\
\text { sequence }\end{array}$ & $\begin{array}{c}\text { net paym. } \\
\text { 2nd mover } \\
\text { cont. X }\end{array}$ & $\begin{array}{c}\text { net paym. } \\
\text { 2nd mover } \\
\text { cont. Y }\end{array}$ \\
\hline \{yes; yes $\}$ & $\{$ low; high\} & 2.5 & 2.1 \\
\hline \{yes; yes & $\{$ high; high $\}$ & 2.1 & 2.5 \\
\hline no; no & $\{$ low; high $\}$ & 3.4 & 3 \\
\hline no; no & $\{$ high; high & 3 & 3.4 \\
\hline
\end{tabular}

The experiment is carried out on the computer. The computer will determine the results in each period by a random draw with the probabilities as they are given in the decision tree.

Information. After each round the first-mover will be informed about his current round payoff.

After each round the second-mover will be informed about current round outcomes and his own payoff.

Payoff. With the completion of the 10 decision rounds you will receive the sum of your payments of every round in cash.

\section{B Appendix: Tables}

\section{Table B1: Probabilities of net payoffs}

\begin{tabular}{ccccc} 
effort & \multicolumn{4}{c}{ output sequence } \\
& $\left(x^{L}, x^{L}\right)$ & $\left(x^{H}, x^{L}\right)$ & $\left(x^{L}, x^{H}\right)$ & $\left(x^{H}, x^{H}\right)$ \\
\hline$(0,0)$ & 0.463 & 0.264 & 0.138 & 0.136 \\
\hline$(0,1)$ & 0.402 & 0.200 & 0.198 & 0.200 \\
\hline$(1,0)$ & 0.110 & 0.344 & 0.090 & 0.456 \\
\hline$(1,1)$ & 0.066 & 0.136 & 0.134 & 0.664 \\
\hline
\end{tabular}

Table B2: State contingent payoffs (in $€$ ) under different contracts

\begin{tabular}{|c|c|c|c|c|}
\hline \multirow{3}{*}{$\frac{\text { output seq. }}{\left(x^{L}, x^{L}\right)}$} & \multicolumn{2}{|c|}{ contract } & \multicolumn{2}{|c|}{ contract } \\
\hline & $\begin{array}{l}N \\
\text { 2nd I } \\
\text { (ag }\end{array}$ & $\begin{array}{l}M \\
\text { lover } \\
\text { nt) }\end{array}$ & $\begin{array}{l}N \\
\text { 1st r } \\
\text { (prir }\end{array}$ & $\begin{array}{r}M \\
\text { over } \\
\text { ipal) }\end{array}$ \\
\hline & 0.90 & 0.90 & 0.60 & 0.60 \\
\hline$\left(x^{H}, x^{L}\right)$ & 1.30 & 1.30 & 1.20 & 1.20 \\
\hline$\left(x^{L}, x^{H}\right)$ & 3.40 & 3.00 & 1.20 & 1.60 \\
\hline$\left(x^{H}, x^{H}\right)$ & 3.00 & 3.40 & 1.80 & 1.40 \\
\hline
\end{tabular}




\section{References}

Abeler, Johannes, Steffen Altmann, Sebastian Kube, and Matthias Wibral (2006): Reciprocity and Payment Schemes: When Equality is Unfair, Working Paper, SSRN, http://papers. ssrn.com/sol3/papers.cfm?abstract_id=955819 (Access date: 2010-03-29).

Anderhub, Vital, Simon Gächter, and Manfred Königstein (2002): Efficient Contracting and Fair Play in a Simple Principal-Agent Experiment, Experimental Economics, 5 (1): 5-27.

Arrow, Kenneth Joseph and Frank H. Hahn (1980): General Competitive Analysis, $5^{\text {th }}$ ed., North-Holland: Amsterdam.

Bailey, Charles D. , Lawrence D. Brown, and Anthony F. Cocco (1998): The Effects of Monetary Incentives on Worker Learning and Performance in an Assembly Task, The Journal of Management Accounting Research, 10: 119-131.

Baker, George P., Michael C. Jensen, and Kevin J. Murphy (1988): Compensation and Incentives: Practice vs. Theory, The Journal of Finance, 43 (3): 593-616.

Balsam, Steven (2002): An Introduction to Executive Compensation, Academic Press: San Diego.

Barney, Jay B. and Mark H. Hansen (1994): Trustworthiness as a Source of Competitive Advantage, Strategic Management Journal, 15 (Special Issue: Computative Organizational Behaviors): 175-190.

Bartolome, Charles A. M. de (1995): Which Tax Rate Do People Use: Average or Marginal?, Journal of Public Economics, 56 (1): 79-96.

Bolton, Gary E. and Axel Ockenfels (2000): ERC: A Theory of Equity, Reciprocity, and Competition, The American Economic Review, 90 (1): 166-193.

Bonner, Sarah E. , Reid Hastie, Geoffrey B. Sprinkle, and S. Mark Young (2000): A Review of the Effects of Financial Incentives on Performance in Laboratory Tasks: Implications for Management Accounting, Journal of Management Accounting Research, 12 (1): 19-64.

Charness, Gary, Guillaume R. Frechette, and John H. Kagel (2004): How Robust is Laboratory Gift Exchange?, Experimental Economics, 7 (2): 189-205.

Charness, Gary and Matthew Rabin (2002): Understanding Social Preferences with Simple Tests, The Quarterly Journal of Economics, 117 (3): 817-869.

Christensen, Peter Ove and Gerald A. Feltham (2005): Economics of Accounting: Performance Evaluation, Springer: Heidelberg.

DeGroot, Morris H. (1970): Optimal Statistical Decisions, McGraw-Hill: New York.

Dutta, Sunil and Stefan Reichelstein (2003): Leading Indicator Variables, Performance Measurement, and Long-Term Versus Short-Term Contracts, Journal of Accounting Research, 41 (5): 837-866.

Falk, Armin and Urs Fischbacher (2006): A Theory of Reciprocity, Games and Economic Behavior, 54 (2): 293-315.

Falk, Armin and Simon Gächter (2002): Reputation and Reciprocity: Consequences for the Labour Relation, The Scandinavian Journal of Economics, 104 (1): 1-26.

Fehr, Ernst, Simon Gächter, and Georg Kirchsteiger (1997): Reciprocity as a Contract Enforcement Device: Experimental Evidence, Econometrica, 65 (4): 833-860.
Fehr, Ernst, Georg Kirchsteiger, and Arno Riedl (1993): Does Fairness Prevent Market Clearing? An Experimental Investigation, The Quarterly Journal of Economics, 108 (2): 437-459.

Fehr, Ernst, Georg Kirchsteiger, and Arno Riedl (1998): Gift Exchange and Reciprocity in Competitive Experimental Markets, European Economic Review, 42 (1): 1-34.

Fehr, Ernst, Alexander Klein, and Klaus M. Schmidt (2004): Contracts, Fairness, and Incentives, CESifo Working Paper Series No. 1215, SSRN, http://papers.ssrn.com/sol3/papers.cfm/ ?abstract_id=549224 (Access date: 2010-03-29).

Fehr, Ernst and Klaus M. Schmidt (1999): A Theory of Fairness, Competition, and Cooperation, The Quarterly Journal of Economics, 114 (3): 817-868.

Fehr, Ernst and Klaus M. Schmidt (2001): Theories of Fairness and Reciprocity: Evidence and Economic Applications, Working Paper, Department of Economics: University of Zurich.

Fehr, Ernst and Klaus M. Schmidt (2004): Fairness and Incentives in a Multi-Task Principal-Agent-Model, The Scandinavian Journal of Economics, 106 (3): 453-474.

Feltham, Gerald A. and Jim Xie (1994): Performance Measure Congruity and Diversity in Multi-Task Principal/Agent Relations, The Accounting Review, 69 (3): 429-453.

Feltham, Gerald A. , Christian Hofmann, and Thomas Hemmer (2007): Limited Commitment in Multi-agent Contracting, Contemporary Accounting Research, 24 (2): 345-375.

Fischbacher, Urs (2007): z-Tree: Zurich Toolbox for ReadyMade Economic Experiments, Experimental Economics, 10 (2): $171-178$

Gächter, Simon and Christian Thöni (2009): Social Comparison and Performance: Experimental Evidence on the Fair WageEffort Hypothesis, Working Paper, Department of Economics: University of St. Gallen.

Gneezy, Uri (2002): Does High Wages Lead to High Profits? An Experimental Study of Reciprocity Using Real Effort, Working Paper, The University of Chicago.

Greiner, Ben (2004): The Online Recruitment System ORSEE 2.0: A Guide for the Organization of Experiments in Economics, Working Paper, Department of Economics: University of Cologne.

Grossman, Sanford J. and Oliver D. Hart (1983): An Analysis of the Principal-Agent Problem, Econometrica, 51 (1): 7-45.

Güth, Werner, Wolfgang Klose, Manfred Königstein, and Joachim Schwalbach (1998): An Experimental Study of a Dynamic Principal-Agent Relationship, Managerial and Decision Economics, 19 (4-5): 327-341.

Hart, Oliver and Bengt Holmström (1987): The Theory of Contracts, in: Truman Fassett Bewley (ed.): Advances in Economic Theory: Fifth World Congress, Cambridge University Press: Cambridge, 71-155.

Holmström, Bengt and Paul Milgrom (1987): Aggregation and Linearity in the Provision of Intertemporal Incentives, Econometrica, 55 (2): 303-328.

Huck, Steffen, Andrew J. Seltzer, and Brian Wallace (2004): Deferred Compensation and Gift Exchange: An Experimental Investigation into Multi-Period Labor Markets, Working Paper, SSRN, http://papers.ssrn.com/sol3/papers.cfm?abstract_id= 564572 (Access date: 2010-03-30).

Indjejikian, Raffi and Dhananjay Nanda (1999): Dynamic Incentives and Responsibility Accounting, Journal of Accounting and Economics, 27 (2): 177-201. 
Jenkins, G. Douglas. Jr. , Nina Gupta, Atul Mitra, and Jason D. Shaw (1998): Are Financial Incentives Related to Performance? A Meta-Analytic Review of Empirical Research, Journal of Applied Psychology, 83 (5): 777-787.

Keser, Claudia and Marc Willinger (2000): Principals' Principles When Agents' Action Are Hidden, International Journal of Industrial Organization, 18 (1): 163-185.

Lazear, Edward P. (2000): Performance Pay and Productivity, The American Economic Review, 90 (5): 1346-1361.

Leonard, Jonathan S. (1990): Executive Pay and Firm Performance, Industrial and Labor Relations Review, 43 (3, Special Issue): 1-29.

Levine, David K. (1998): Modelling Altruism and Spitefulness in Experiments, Review of Economic Dynamics, 1 (3): 593-622.

Lukas, Christian (2007a): Get More for Less? Experimental Evidence on Repeated Decision Making under Non-monotone Incentives, Zeitschrift für Betriebswirtschaft, 77 (4): 351-378.

Lukas, Christian (2007b): Managerial Expertise, Learning Potential, and Dynamic Incentives: Get More for Less?, Managerial and Decision Economics, 28 (3): 195-211.

Nachman, David C. and Tom H. Noe (1995): Operating Efficiency and Output Insensitive Employment Contracts for Capital Management, Economic Theory, 5 (2): 315-335.

Nalbantian, Haig R. and Andrew Schotter (1997): Productivity under Group Incentives: An Experimental Study, The American Economic Review, 87 (3): 314-341.

Nowak, Martin and Karl Sigmund (1993): A Strategy of WinStay, Lose-Shift that Outperforms Tit-For-Tat in the Prisoner's Dilemma Game, Nature, 364: 56-58.

Prendergast, Canice (2002): The Tenous Trade-off between Risk and Incentives, Journal of Political Economy, 110 (5): 1071-1102.

Rabin, Matthew (1993): Incorporating Fairness into Game Theory and Economics, The American Economic Review, 83 (5): 1281-1302.

Rabin, Matthew (1998): Psychology and Economics, Journal of Economic Literature, 36 (1): 11-46.

Roth, Alvin E. and Michael W. K. Malouf (1979): GameTheoretic Models and the Role of Information in Bargaining, Psychological Review, 86 (6): 574-594.

Sabac, Florin (2007): Dynamic Agency with Renegotiation and Managerial Tenure, Management Science, 53 (5): 849-864.

Bull, Clive, Andrew Schotter, and Keith Weigelt (1987): Tournaments and Piece Rates: An Experimental Study, Journal of Political Economy, 95 (1): 1-33.

Selten, Reinhard, Abdolkarim Sadrieh, and Klaus Abbink (1999): Money Does Not Induce Risk Neutral Behavior, but Binary Lotteries Do even Worse, Theory and Decision, 46 (3): 213-252.

Sprinkle, Geoffrey B. (2000): The Effect of Incentive Contracts on Learning and Performance, The Accounting Review, 75 (3): 299-326.

Van der Heijden, Eline C. M. , Jan H. M. Nelissen, Jan J. M. Potters, and Harrie A. A. Verbon (2001): Simple and Complex Gift Exchange in the Laboratory, Economic Inquiry, 39 (2): 280-297.

\section{Biographies}

Jeannette Brosig holds a full professorship for Quantitative Economic Policy at the University Duisburg-Essen. She obtained her doctoral degree in March 2003 and received her Habilitation in January 2008 at the Otto-von-GuerickeUniversity of Magdeburg. During this period she also stayed at Penn State University as a research fellow (2004) and served as the managing director of the Magdeburg Laboratory for Experimental Economics (2005-2008). From 2006 to 2008 she taught at the University of Cologne ("Lehrstuhlvertretung"). Prof. Brosig is the director of the Laboratory for Experimental Economics at the University of Duisburg-Essen. Her areas of research include market design, experimental economics, and game theory.

Christian Lukas is Junior Professor in Accounting and Business Administration at the University of Konstanz since 2005. He received his doctoral degree in 2005 from the Otto-von-Guericke University of Magdeburg. His areas of research include dynamic performance measurement, managerial accounting, and experimental agency.

Thomas Riechmann is Professor of Microeconomics at the University of Kaiserslautern. He received his doctoral degree in 2000 at the University of Hannover and worked as a research assistant at the Otto-von-Guericke University of Magdeburg. His research areas include applied game theory, experimental economics, and industrial organization. 